\title{
Current and future treatment strategies in chronic lymphocytic leukemia
}

\author{
Krish Patel ${ }^{*}$ (1) and John M. Pagel
}

\begin{abstract}
Treatment decisions for patients with chronic lymphocytic leukemia (CLL) are dependent on symptoms and classification into high-, medium-, or low-risk categories. The prognosis for CLL hinges, in part, on the presence or absence of less-favorable genetic aberrations, including del(17p), del(11q), TP53 dysfunction, and IGHV mutations, as these markers are associated with worse treatment response. Promising results from multiple clinical trials show emerging therapies targeting Burton tyrosine kinase, B-cell leukemia/lymphoma 2, and phosphatidylinositol 4,5-bisphosphate 3-kinase catalytic subunit delta result in better outcomes and prolonged progression-free survival for patients both with and without certain high-risk aberrations. Favorable outcomes using these novel oral targeted therapies, either alone or in combination with other treatments such as anti-CD20 antibodies, has led to their use almost entirely supplanting chemoimmunotherapy in the treatment of CLL. In this narrative review, we summarize the current clinical evidence for the use of targeted mono- and combination therapies for CLL, discuss new and next-generation treatment approaches currently in development, and provide insight into areas of unmet need for the treatment of patients with CLL.
\end{abstract}

Keywords Chronic lymphocytic leukemia, BTK inhibitors, Emerging treatment, Treatment strategy

\section{Background}

Chronic lymphocytic leukemia (CLL) is the most common leukemia in Western countries [1] and affects more men than women (a ratio of approximately 1.7:1), with a median age at diagnosis of 67-72 years [2-4]. As a disease of neoplastic mature clonal B lymphocytes, B-cell receptor signaling plays an important role in the survival of CLL cells [5]. Typical clinical signs of active CLL include anemia, thrombocytopenia, and lymphocytosis; symptoms include unintentional weight loss, fatigue, fevers, and drenching night sweats $[1,6]$. Overall survival (OS) of patients with CLL at 5 years ranges from about $20 \%$ among very high-risk patients to more than $90 \%$ in those with less-aggressive genetic risk features [7]. CLL

\section{*Correspondence:}

Krish Patel

krish.patel@swedish.org

Center for Blood Disorders and Stem Cell Transplantation, Swedish Cancer

Institute, 1221 Madison St, Seattle, WA 98104, USA and small lymphocytic lymphoma (SLL) are different clinical presentations of the same pathologic disease and are commonly referred to together as CLL.

Novel, oral, targeted therapies have almost entirely supplanted chemoimmunotherapy in the treatment of CLL. These novel therapies include inhibitors of Bruton tyrosine kinase (BTK), apoptosis regulator B-cell leukemia/ lymphoma 2 (BCL-2), and phosphatidylinositol 4,5-bisphosphate 3-kinase catalytic subunit delta (PI3K 8 ).

In addition to monotherapy with these oral targeted agents, combinations with other types of therapies are also common. One example is combination therapy with select targeted agents and anti-CD20 monoclonal antibodies (eg, rituximab, ofatumumab, or obinutuzumab) [8]. Emerging therapies include novel chemotherapy-free triplet combinations, bispecific antibody-based, and cellbased therapies for CLL [9-11]. Here we review current and potential future treatment strategies for patients with CLL and explain the underlying rationales, with a focus on real-world evidence. original author(s) and the source, provide a link to the Creative Commons licence, and indicate if changes were made. The images or other third party material in this article are included in the article's Creative Commons licence, unless indicated otherwise in a credit line to the material. If material is not included in the article's Creative Commons licence and your intended use is not permitted by statutory regulation or exceeds the permitted use, you will need to obtain permission directly from the copyright holder. To view a copy of this licence, visit http://creativecommons.org/licenses/by/4.0/. The Creative Commons Public Domain Dedication waiver (http://creativeco mmons.org/publicdomain/zero/1.0/) applies to the data made available in this article, unless otherwise stated in a credit line to the data. 


\section{Decision to treat}

The decision to start treatment of CLL depends on the patient's symptoms and risk of disease progression [6]. Low-, intermediate-, or high-risk is determined using the widely accepted Rai and Binet clinical-staging systems $[12,13]$. Additionally, the CLL international prognostic index (CLL-IPI) combines clinical staging with age, the presence of leukemia cells with TP53 aberrations or unmutated $I G H V$, and serum $\beta 2$-microglobulin levels [7]. Treatment is generally indicated in patients with symptomatic or active disease, but not typically among those with no symptoms, as set out in the International Workshop on CLL (iwCLL) guidelines [6]. Prognostic markers are important to consider when deciding how to treat a patient. Less-favorable CLL prognostic markers such as del(17p) or TP53 dysfunction do not lead to long-term remissions with standard chemoimmunotherapy and patients with these disease features are best treated with novel agents [14].

\section{Consideration of health-related quality of life}

Optimizing health-related quality of life (HRQoL) and managing adverse events (AEs) are also important considerations in the decision to treat and choice of therapy. A 2016 systematic literature review found that greater disease severity was a predictor of poor HRQoL [15]. Comparisons of treated and untreated populations demonstrated small positive effects on HRQoL in favor of treated populations, but HRQoL differences between the treatments were small [15]. However, HRQoL may affect treatment adherence [16]. A retrospective US commercial claims database study reported that the number of AEs experienced by a patient was a significant predictor of poor adherence to oral targeted therapies for hematologic malignancies [17]. In addition to affecting HRQoL, AEs can lead to increased economic burden. The economic burden of AEs in patients receiving CLL therapy was reported to be substantial in a retrospective insurance database study [18]. Because of the toxicity associated with continuous long-term targeted therapy, consideration should be given to the use of limited-duration combination therapies when appropriate [19].

\section{Early intervention}

A phase 3 trial (NCT02863718) was recently conducted to evaluate early-stage treatment of CLL in patients with disease that was not indicated for treatment according to iwCLL guidelines [20]. Patients with Binet stage A disease (with intermediate, high, or very high risk of disease progression) were treated with ibrutinib or placebo. Event-free survival was 47.8 months in the placebo group and not reached in the ibrutinib group at a median follow-up of 31 months; progression-free survival (PFS) was 14.8 months and not reached, respectively. Incidence rates of AEs were similar in both groups. This study demonstrates that early intervention can provide clinical benefit to patients with CLL.

\section{Current treatment strategies}

\section{BTK inhibitors}

BTK inhibitors have become a recommended first-line treatment option in patients with CLL, whether or not they have TP53 dysfunction, and whether or not their disease has relapsed or become refractory on other treatments [8]. BTK-inhibitor monotherapy is associated with remarkable single-agent efficacy and favorable toxicity compared with chemoimmunotherapy [21]. BTK inhibitors approved for treatment of CLL at the time of writing are ibrutinib and acalabrutinib; others are currently in development (discussed in the "Future treatment strategies" section).

Despite the current treatment guidelines and notable efficacy with BTK inhibitors, an interim analysis from a prospective observational registry study (informCLL) indicated that, in the real-world setting, the transition to BTK inhibitor use according to treatment guidelines has been slow [22]. The study reported that, in 2020, chemoimmunotherapy was still the most common first-line therapy for treatment-naïve patients and that the BTK inhibitor, ibrutinib, was the most commonly used among patients being treated for relapsed or refractory CLL [22]. The informCLL registry also showed that many patients with TP53 dysfunction received chemotherapy in the real-world setting [22], despite treatment guidelines recommending against chemotherapy in these patients because of the primary ineffectiveness of chemotherapy in this subgroup [6, 8]. Moreover, prognostic genetic testing is required to determine whether TP53 dysfunction is present, but testing rates were reportedly low [22], which likely accounts for some patients being treated differently from treatment-guideline recommendations.

Patients who were considered high-risk because of del(17p), del(11q), unmutated IGHV, or TP53 dysfunction when chemotherapy was the only available first-line therapy, have much-improved outcomes with BTK-inhibitor therapy. For some risk markers, BTK inhibitors appear to have changed the definition of high risk. For example, when patients were treated with ibrutinib as first-line, those with del(11q) were reported to have a comparable PFS to those without [23], and PFS may be similar whether a patient has CLL with unmutated or mutated IGHV [24]. However, del(17p) and TP53 mutation or deletion remains a risk factor for disease progression on BTK-inhibitor therapy [24].

Ibrutinib was the first BTK inhibitor investigated for the treatment of patients with CLL. Approval for the 
treatment of patients with relapsed or refractory CLL was obtained in February 2014 [25] and, in March 2016, approval was obtained for treatment-naïve patients with CLL [26]. As of 2019, ibrutinib has been recommended as an option for first-line therapy for all patients with CLL under the National Comprehensive Cancer Network guidelines [27].

The efficacy of ibrutinib compared with chemoimmunotherapy has been established in randomized controlled trials in various settings. The findings from these studies are summarized in Table 1. Briefly, the RESONATE trial showed improved PFS, OS, and overall response rate (ORR) for ibrutinib versus ofatumumab in patients with previously treated CLL [28]. In treatment-naïve patients, ibrutinib was superior to chlorambucil in the RESONATE-2 trial (PFS, OS, and ORR) [29] and the iLLUMINATE trial showed significantly improved PFS with ibrutinib plus obinutuzumab versus chlorambucil plus obinutuzumab [30]. Improved PFS and OS were reported for ibrutinib plus rituximab versus fludarabine plus cyclophosphamide plus rituximab for fit treatment-naïve patients with CLL who were under the age of 70 years in the ECOG1912 trial [31]. Ibrutinib with or without rituximab also improved PFS (but not OS at short follow-up) versus bendamustine plus rituximab in older ( $\geq 65$ years) treatment-naïve patients with CLL (ALLIANCE trial); importantly, the addition of rituximab to ibrutinib did not provide any additional benefit versus ibrutinib alone [32].

While ibrutinib is generally well-tolerated, treatment discontinuations or interruptions due to toxicity may limit the efficacy of ibrutinib in patients receiving continuous oral therapy. A recent review reported that discontinuation rates for ibrutinib were similar between clinical trials and real-world practice (32\% vs $34 \%$, respectively), though the reasons for discontinuation differed [33]. One large-scale, real-world study reported that $41 \%$ of patients discontinued ibrutinib and that ibrutinib toxicity was the main reason for these discontinuations [34]. A single-center, real-world study reported that $24 \%$ of patients discontinued ibrutinib due to serious adverse events (SAEs), and $55 \%$ of patients had a dose interruption of at least 1 week [35]. Temporary ibrutinib interruption was associated with shorter event-free survival in a retrospective study of patients treated outside of clinical trials at the Mayo Clinic [36] and a post hoc analysis of two phase 3 studies (RESONATE and RESONATE-2) found that outcomes after ibrutinib discontinuation were better in patients who received ibrutinib in earlier rather than later lines of therapy [37]. In addition to possibly affecting outcomes, AEs can affect patient willingness to adhere to treatment.
One aspect identified for improvement with BTK inhibitors is to reduce drug-associated toxicities. BTK inhibitors have varying affinities for related and unrelated ATP-binding kinases that contain sterically available cysteines, including epidermal growth factor receptor (EGFR), human EGFR-2 (HER2), human EGFR-4 (HER4), interleukin-2-inducible T-cell kinase (ITK), bone marrow tyrosine kinase gene in chromosome $\mathrm{X}$ (BMX), Janus kinase 2 (JAK2), TEC protein tyrosine kinase, and B-lymphocyte kinase (BLK) [38]. Off-target inhibition by these kinases may contribute to many of the toxicities associated with these agents [38], making BTK inhibitors with a higher selectivity potentially more attractive than those with a lower selectivity.

The BTK inhibitor arsenal has expanded recently with the November 2019 approval of acalabrutinib for the treatment of adult patients with CLL [39]. Acalabrutinib is a second-generation BTK inhibitor with reduced off-target activity and improved in vitro selectivity compared with ibrutinib [40]. This greater selectivity for BTK may result in improved efficacy and tolerability. Another BTK inhibitor, zanubrutinib, is currently in development and is discussed later in this review ("BTK inhibitors in development" section); however, it is noted here that, like acalabrutinib, zanubrutinib appears to have greater selectivity than ibrutinib.

Multiple clinical trials in various clinical settings have been conducted to assess the safety and efficacy of acalabrutinib for the treatment of CLL; key studies are summarized in Table 1 . The first phase $1 / 2$ study in patients with relapsed CLL demonstrated that acalabrutinib treatment was well-tolerated [41]. After a median follow-up of 41 months, median PFS was not reached, and acalabrutinib showed favorable safety, response, and durability of response; of note, responses were similar among all patients, including those with $\operatorname{del}(17 \mathrm{p})$, TP53 dysfunction, unmutated $I G H V$, del(11q), or complex karyotype [42]. The pivotal clinical trial (ELEVATE TN) compared acalabrutinib monotherapy or acalabrutinib plus obinutuzumab to chlorambucil plus obinutuzumab in treatment-naïve patients with CLL who were over the age of 65 years or who had significant comorbidities [43]. In this trial, acalabrutinib demonstrated an acceptable safety profile and significantly improved PFS (for both acalabrutinib and acalabrutinib plus obinutuzumab) versus chlorambucil plus obinutuzumab, which was consistent across subgroups, including patients with high-risk genetic aberrations [43]. Further, interim analysis of the ASCEND phase 3 study demonstrated superiority of acalabrutinib to rituximab plus idelalisib/bendamustine in prolonging PFS in patients with relapsing or refractory CLL, including those with del(17p) or TP53 mutation or 


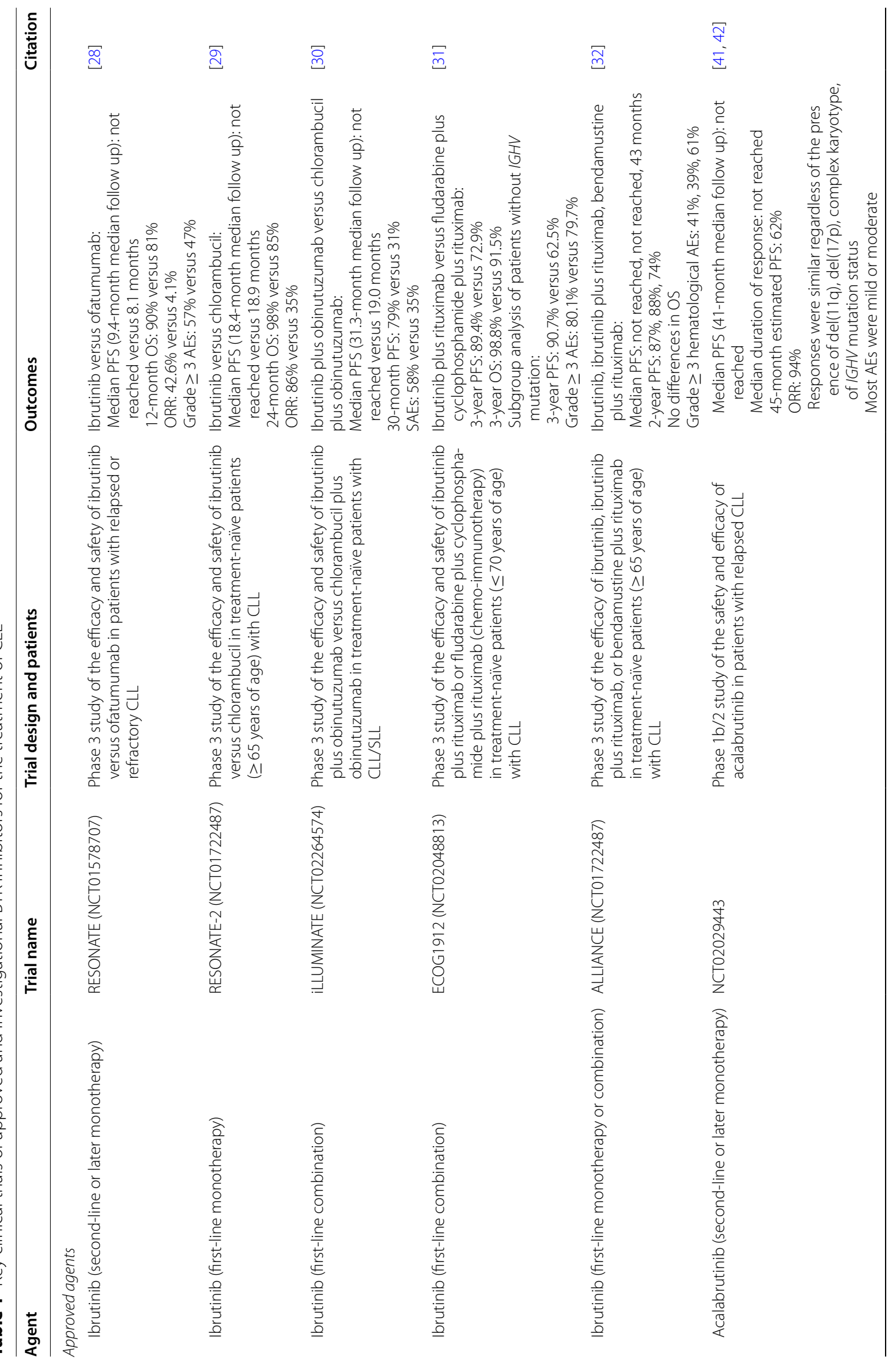




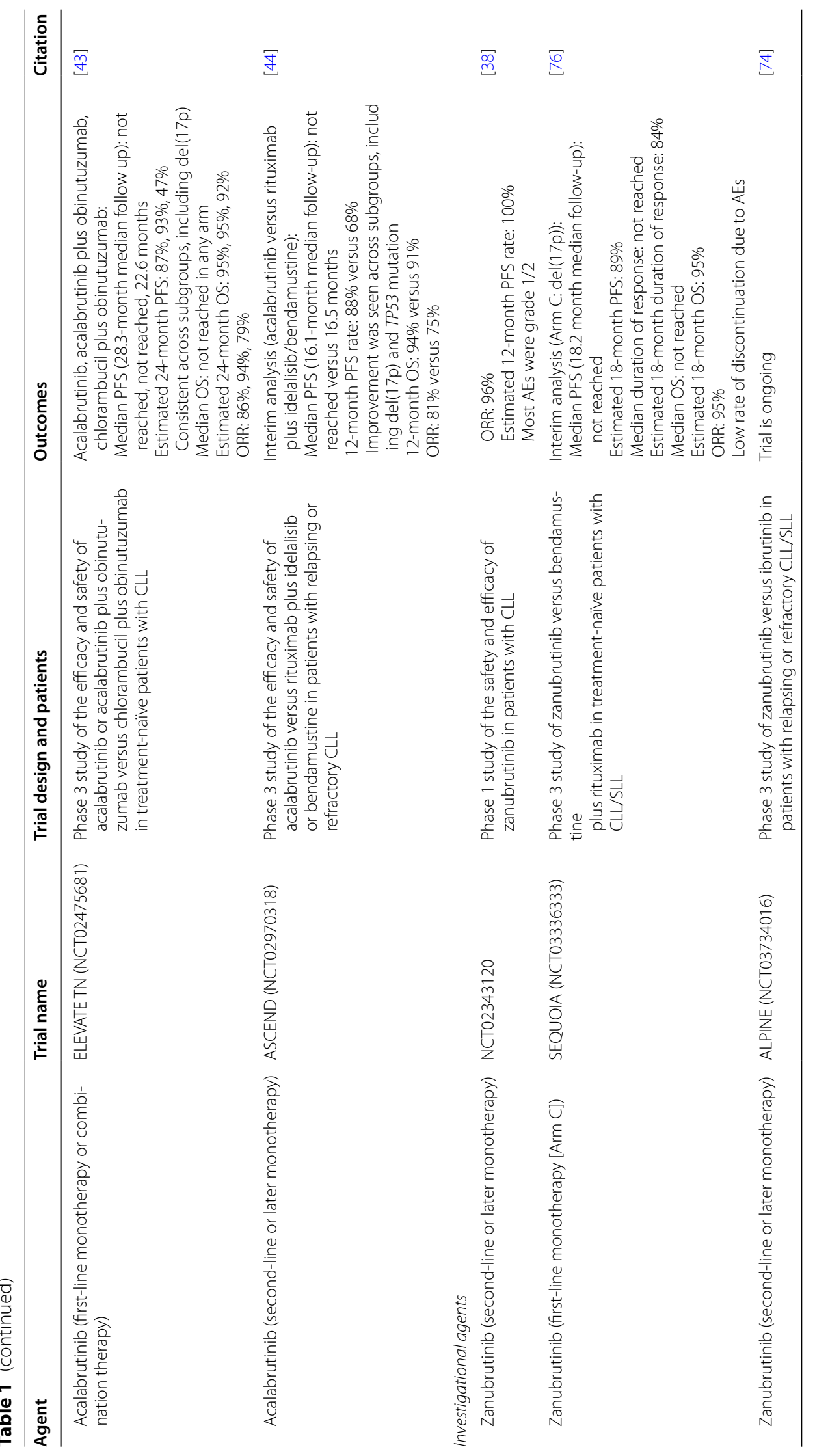




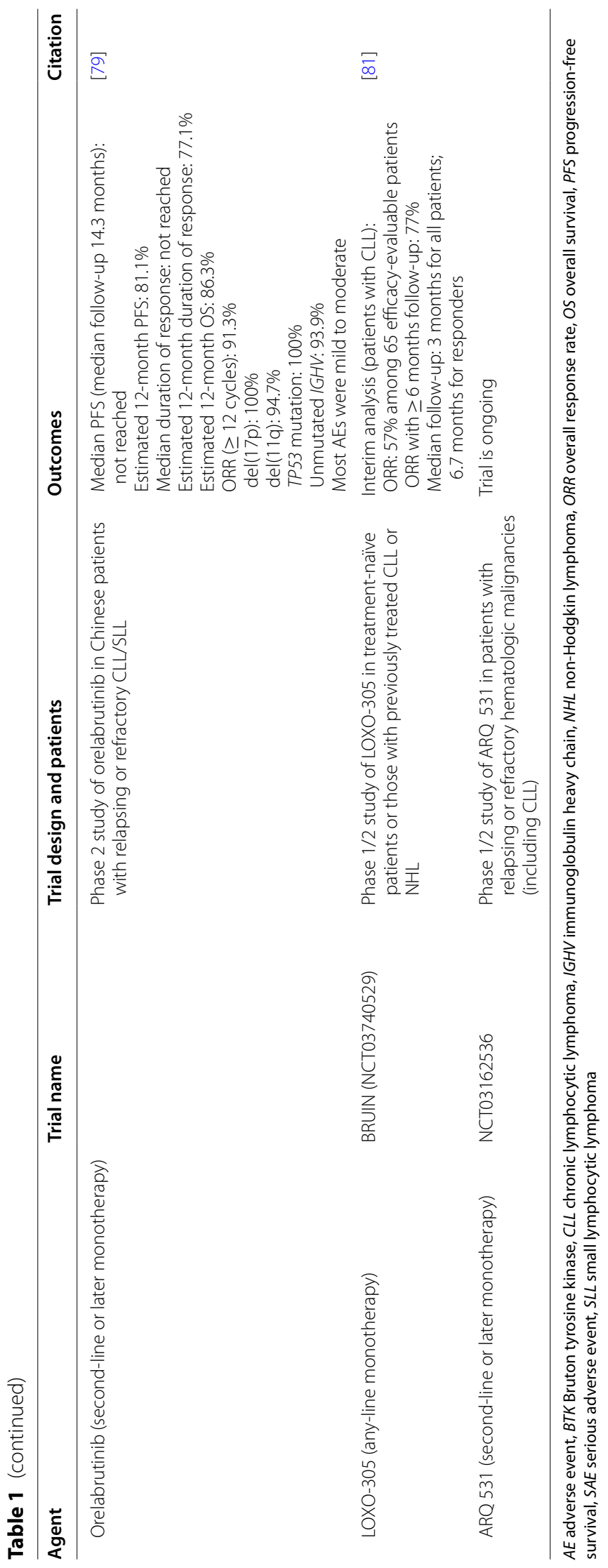


deletion, and showed acalabrutinib to have a more tolerable safety profile [44].

Acalabrutinib has also shown acceptable tolerability in patients who were intolerant to ibrutinib [40, 45], providing an option for continuing BTK-inhibitor therapy in these patients. Most recently, a not-yet published clinical trial, ELEVATE RR, has been completed comparing acalabrutinib directly with ibrutinib in patients with previously treated high-risk CLL (NCT02477696). The results of this trial may have the potential to change clinical practice in favor of acalabrutinib.

As with most cancer therapies, resistance to treatment can develop. In the case of current-generation BTK inhibitors, acquired mutations in $B T K$ that affect the active site or are immediately downstream of the effector phospholipase $\mathrm{C} \gamma 2$ (PLCG2) can lead to BTK-inhibitor resistance and relapse in patients with CLL $[46,47]$. Therefore, there is a need to identify and develop next-line therapies for these patients who develop BTK-inhibitor resistance and to understand how to identify the optimal treatment sequence for each individual patient.

\section{Inhibitors of BCL-2 and PI3K $\delta$}

\section{$B C L-2$ inhibitor}

Other approved drug classes for treating CLL include BCL-2 and PI3K $\delta$ inhibitors; key clinical trials investigating their efficacy and safety are summarized in Table 2 (BCL-2 inhibitors) and Table 3 (PI3K $\delta$ inhibitors). Venetoclax was the first, and remains the only, approved BCL-2 inhibitor for the treatment of patients with relapsed high-risk CLL. It was initially approved in April 2016 for the treatment of patients with del(17p) CLL who had received at least 1 prior line of therapy [48]. Approval was based on the results of the pivotal phase 2 study, which was conducted in patients with del(17p) CLL [49, 50]. Subsequently, the combination of venetoclax plus obinutuzumab for a fixed duration was approved for treatment-naïve patients with CLL in May 2019 [48] based on the results of the CLL14 trial [51]. This study reported that venetoclax plus obinutuzumab given for just 1 year significantly prolonged PFS versus chlorambucil plus obinutuzumab, including in those patients with del(17p), TP53 mutation or deletion, or unmutated IGHV status [51]. Given the current treatment landscape, venetoclax plus obinutuzumab has emerged as another important first-line treatment option, as well as the most obvious first-line treatment, for patients with TP53 dysfunction and unmutated $I G H V$ who are not suitable candidates for BTK-inhibitor monotherapy. It should be noted that follow-up efficacy results from the CLL14 trial, however, suggest that outcomes in patients having disease with TP53 mutation or deletion may not be as durable, with relatively earlier relapses after therapy discontinuation [52]. A recent real-world study of patients with

Table 2 Key clinical trials of approved BCL-2 inhibitors for the treatment of CLL

\begin{tabular}{|c|c|c|c|c|}
\hline Agent & Trial name & Trial design and patients & Outcomes & Citation \\
\hline $\begin{array}{l}\text { Venetoclax (second-line or } \\
\text { later monotherapy) }\end{array}$ & NCT01889186 & $\begin{array}{l}\text { Phase } 2 \text { single-arm study of the } \\
\text { safety and efficacy of venetoclax in } \\
\text { patients with del(17p) relapsed or } \\
\text { refractory CLL }\end{array}$ & $\begin{array}{l}\text { ORR: } 12.1 \text {-month median } \\
\text { follow-up, } 79.4 \% \text {; final, } 77 \% \\
\text { 24-month PFS: } 54 \% \\
\text { SAEs: } 12.1 \text {-month median } \\
\text { follow-up, 55\%; final, 58\% }\end{array}$ & {$[49,50]$} \\
\hline $\begin{array}{l}\text { Venetoclax (first-line } \\
\text { combination therapy) }\end{array}$ & CLL14 (NCT02242942) & $\begin{array}{l}\text { Phase } 3 \text { study of the efficacy and } \\
\text { safety of venetoclax plus obinutu- } \\
\text { zumab versus chlorambucil plus } \\
\text { obinutuzumab in treatment-naïve } \\
\text { patients with CLL who have coex- } \\
\text { isting conditions }\end{array}$ & $\begin{array}{l}\text { Venetoclax plus obinutuzumab } \\
\text { versus chlorambucil plus } \\
\text { obinutuzumab: } \\
\text { 24-month PFS: } 88.2 \% \text { versus } \\
64.1 \% \\
\text { Results were similar for TP53 } \\
\text { deletion/mutation or unmu- } \\
\text { tated IGHV } \\
\text { Grade } \geq 3 \text { AEs: } 78.8 \% \text { versus } \\
\text { 76.6\% }\end{array}$ & {$[51]$} \\
\hline $\begin{array}{l}\text { Venetoclax (second-line } \\
\text { or greater combination therapy) }\end{array}$ & MURANO (NCT02005471) & $\begin{array}{l}\text { Phase } 3 \text { study of the efficacy and } \\
\text { safety of venetoclax plus rituximab } \\
\text { versus bendamustine plus rituxi- } \\
\text { mab in patients with relapsed or } \\
\text { refractory CLL/SLL }\end{array}$ & $\begin{array}{l}\text { Venetoclax plus rituximab } \\
\text { versus bendamustine plus } \\
\text { rituximab: } \\
24-\text { month PFS: } 84.9 \% \text { versus } \\
36.3 \% \\
\text { Results were similar for TP53 } \\
\text { deletion or unmutated IGHV } \\
\text { Grade } \geq 3 \text { AEs: } 82.0 \% \text { versus } \\
70.2 \%\end{array}$ & {$[50]$} \\
\hline
\end{tabular}




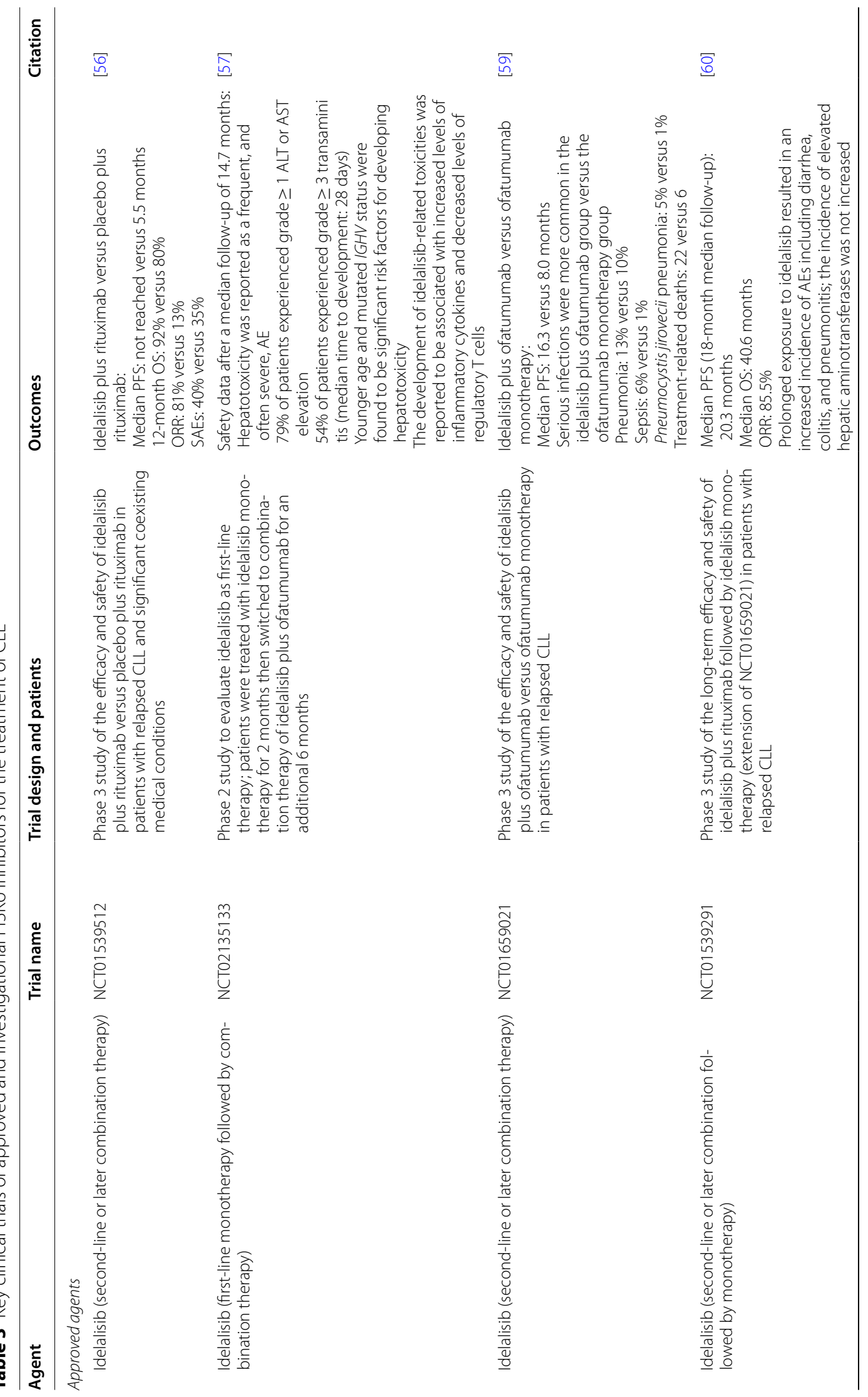




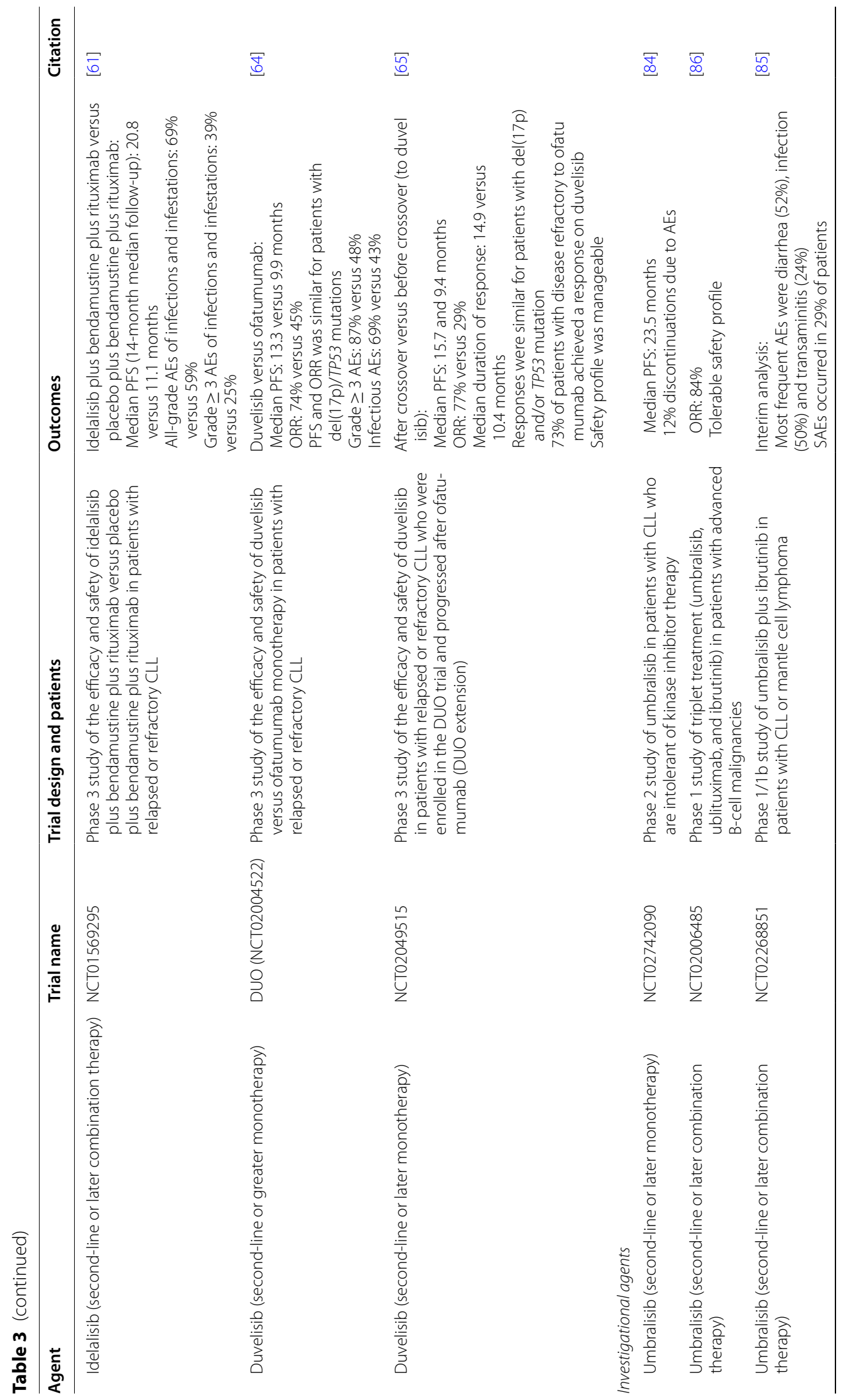




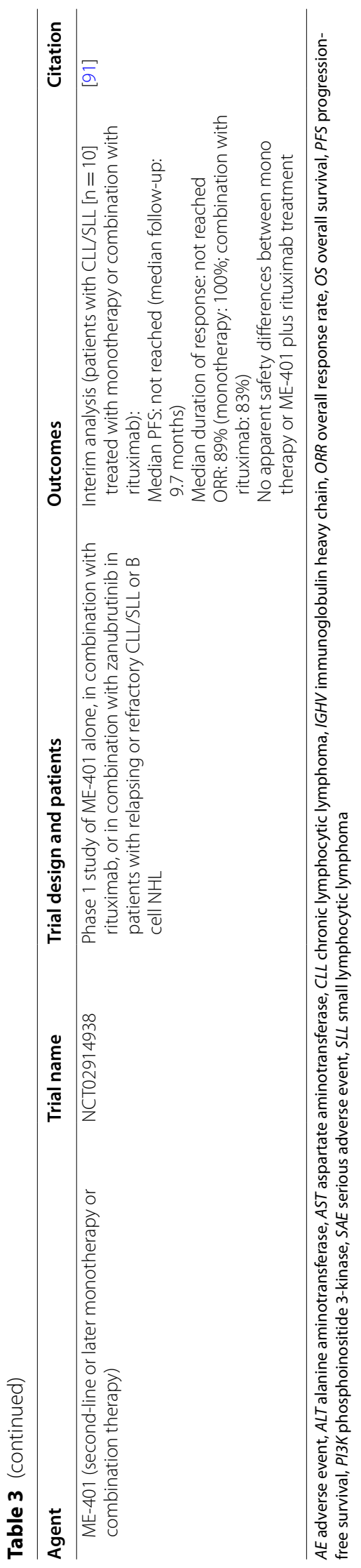


CLL who were treated with venetoclax identified TP53 aberrations as a predictor of inferior PFS [53].

Promising results have also been obtained for treatment of relapsed patients with 2 years of fixed-duration therapy with venetoclax plus rituximab. The MURANO trial reported that this combination resulted in a significantly longer PFS versus bendamustine plus rituximab in patients with relapsed or refractory CLL, regardless of TP53 or IGHV mutation status [50].

It should be noted that venetoclax regimens are generally well-tolerated and effective in patients who were previously treated with ibrutinib $[53,54]$. A recent realworld study of CLL patients treated with venetoclax reported that $29 \%$ of patients discontinued treatment, most commonly due to disease progression, followed by toxicity (mainly hematologic). This study also reported a dose-reduction rate of $21 \%$ [53]. Real-world response rates and durations of responses were noted as comparable to clinical-trial data, with most patients maintaining a maximum recommended dose [53].

A treatment discontinuation rate of approximately $6 \%$ due to treatment-related toxicity leaves an opportunity for improvement in next-generation BCL-2 inhibitors. In addition, the development of venetoclax resistance remains a concern. Resistance may develop because of mutations in $B C L 2$, further highlighting the need to investigate new treatment combinations to determine optimal treatment strategies [21].

\section{PI3K inhibitors}

There are currently 2 PI $3 K \delta$ inhibitors approved for the treatment of CLL. The first of these, idelalisib, was approved for use in combination with rituximab for the treatment of relapsed CLL in 2014 [55]. While idelalisib is highly effective in combination with rituximab [56], its use as first-line therapy was associated with severe immune-mediated hepatoxicities [57, 58], and its use as second-line or later therapy was associated with an increased incidence of serious infections $[59,60]$ and an increase in the incidence of additional immune-mediated AEs with prolonged exposure [60, 61].

Given the toxicity issues, treatment with idelalisib has been limited in comparison to BTK inhibitor treatment. When idelalisib was compared with ibrutinib as a firstkinase inhibitor treatment in a retrospective real-world study, ibrutinib appeared superior [62]. In the randomized phase 3 ASCEND trial, acalabrutinib was superior to idelalisib plus rituximab among patients with relapsed or refractory CLL [44].

Duvelisib is the second, and most recently approved, PI3K $\delta$ inhibitor for CLL treatment [63]. It is a dual inhibitor of phosphatidylinositol 3-kinases PI3K $\delta$ and PI3Ky and was approved in December 2018 for the treatment of patients with relapsed or refractory CLL [63]. While it has demonstrated efficacy in CLL, treatment-associated toxicities have been a concern $[64,65]$. Ongoing research aims to discover approaches to reduce the occurrence of treatment-related immune-mediated toxicities through combination-therapy studies and alternative dosing regimens $[66,67]$. Similar to idelalisib, the toxicities associated with duvelisib treatment have led, in most cases, to consideration for their use after a BTK or BCL-2 inhibitor as a general treatment strategy.

\section{Future treatment strategies}

BTK inhibitors are an effective treatment for patients with CLL; however, there is a need to further improve upon tolerability issues and the development of resistance. AEs associated with BTK-inhibitor treatment reduce both tolerability and HRQoL. While BTK-target selectivity in second-generation BTK inhibitors appears to have reduced off-target effects, they remain susceptible to development of treatment resistance and additional improvement in tolerance is possible.

The development of resistance to irreversible-covalent-binding BTK inhibitors is almost inevitable in most patients with CLL. There is a need to develop treatment strategies or novel therapies that would delay the development of resistance or overcome the issue altogether.

Determining an optimal treatment sequence would likely benefit patient outcomes. As an example, a large, multicenter, retrospective analysis of treatment sequences in patients with CLL was conducted to better understand the optimal treatment sequence for several newer CLL therapies, ibrutinib, idelalisib, and venetoclax [62]. The study found that, in patients who were treated with kinase inhibitors or venetoclax in the setting of prior kinase-inhibitor failure, alternate kinase inhibitors or venetoclax appeared superior to chemoimmunotherapy combinations. The study also reported that ibrutinib appeared superior to idelalisib as the first kinase inhibitor in patients with relapsed CLL. An open-label phase 2 trial assessed venetoclax treatment in patients with relapsed or refractory CLL who had disease progression during or after treatment with ibrutinib [59]. Interim analysis indicated that venetoclax had durable clinical activity, with a median PFS of 24.7 months and 12-month estimates of PFS and OS of $75 \%$ and $91 \%$, respectively. A retrospective chart review found that BTK inhibitor therapy for patients with CLL who had disease progression following venetoclax treatment resulted in durable disease control, with a median PFS of 34 months and a median OS of 42 months after BTK inhibitor initiation [68]. These findings highlight the potential importance of treatment 
sequence on outcomes. With the development of multiple new therapies for CLL, treatment algorithms should be optimized, requiring clinical studies testing different sequencing strategies.

Despite recent advances in CLL therapy, outcomes for patients with TP53 mutation or deletion remain worse than for those without. For example, while BTK inhibitors have improved outcomes for certain patients who were considered high-risk on chemotherapy, TP53 aberration is a risk for progression on BTK-inhibitor therapy [24]. Likewise, a recent real-world study reported a significantly shorter PFS in patients with TP53 deficiency versus without, and identified TP53 dysfunction as a predictor of inferior PFS [53]. Taken together, these findings suggest that there is a need for new targeted therapies and new treatment approaches in the high-risk patient population.

New therapies and treatment strategies should not only aim to improve tolerability and to overcome the development of resistance, but also to extend remission with duration-limited approaches, regardless of risk factors. Next-generation BTK, BCL-2, and PI3K $\delta$ inhibitors that may address shortcomings related to tolerability and resistance are in development. Research into the development of novel therapies or drug combinations with the goal of offering a finite treatment option is needed. New treatment strategies that include novel drug combinations, such as BCL-2/BTK-inhibitor combinations and chemotherapy-free triplet combinations, or minimal residual disease (MRD)-guided treatment have shown promise in recent and ongoing clinical trials. Novel therapies that aim to extend survival and work towards cures, such as bispecific antibodies and chimeric antigen receptor T-cell (CAR-T) therapy, are also being developed.

\section{BTK inhibitors in development}

Next-generation BTK inhibitors aim to reduce the development of resistance, though their improvements over currently approved BTK inhibitors remain under investigation. Those agents currently in development for CLL include zanubrutinib and orelabrutinib, and the reversible noncovalent-binding inhibitors LOXO-305 and ARQ 531. Key clinical trials of these investigational agents are summarized in Table 1. LOXO-305 and ARQ 531 have shown activity against BTK inhibitor-resistant CLL in preclinical studies $[69,70]$ and, while neither is currently approved for the treatment of CLL, both have shown promise in patients with acquired resistance to BTK inhibitors [71, 72].

One of the irreversible BTK inhibitors, zanubrutinib, received accelerated approval in the USA (November 2019) for the treatment of adult patients with mantle cell lymphoma who had received at least 1 previous therapy
[73]. Zanubrutinib is not currently approved for CLL but is under investigation for this indication [74]. Data regarding the dynamics, number, and immunophenotype of immune cells collected from patients with relapsed or refractory CLL and who were undergoing zanubrutinib treatment suggest that zanubrutinib can regulate immunity by improving T-cell exhaustion, inhibiting suppressor cells, and disrupting CLL cell migration through downregulation of adhesion/homing receptors [75]. A phase 1 study demonstrated that zanubrutinib had favorable tolerability and encouraging activity in patients with CLL [38]. Recent results from Arm C (treatment-naive patients with del(17p) CLL) of the phase 3 SEQUOIA trial showed a durable response to zanubrutinib at the median follow-up of 18.3 months and that treatment was generally well-tolerated, with a low rate of discontinuation due to AEs [76]. Direct comparisons of the efficacy and safety of zanubrutinib and ibrutinib have been reported in patients with relapsed Wäldenstrom macroglobulinemia (ASPEN trial; NCT03053440) [77] and are currently underway in patients with relapsed or refractory CLL (ALPINE trial; NCT03734016) [74]. Preliminary results from ASPEN reported that the incidence of atrial fibrillation, contusion, diarrhea, peripheral edema, hemorrhage, muscle spasms, pneumonia, and AEs leading to discontinuation or death were lower with zanubrutinib than ibrutinib [78], demonstrating an apparent improved toxicity profile in patients with Wäldenstrom macroglobulinemia. Whether these toxicity differences may exist in patients with CLL is unknown to date, but such questions will be answered by future and ongoing studies, including ALPINE.

Orelabrutinib is a highly selective irreversible BTK inhibitor that is also in development [79] and was recently approved in China for the treatment of patients with relapsed or refractory CLL/SLL and relapsed or refractory mantle cell lymphoma [80]. Orelabrutinib demonstrated durable response in Chinese patients with relapsed or refractory CLL/SLL, including those with del(17p), del(11q), TP53 mutation, or unmutated $I G H V$, and a favorable safety profile in a recent update of a phase 2 extended study [79].

LOXO-305 is a noncovalent BTK inhibitor that is also under development and currently undergoing a phase $1 / 2$ study (BRUIN trial; NCT03740529) in patients with previously treated CLL or non-Hodgkin lymphoma (NHL). Recent phase 1 data indicated favorable safety and promising efficacy (ORR: 57\%) in heavily pretreated patients with CLL, including those with acquired BTKinhibitor and venetoclax resistance [81]. Follow-up studies will be needed to confirm these results.

Also currently in early-phase clinical trials is ARQ 531, a multikinase inhibitor of BTK- and Src-family kinases. 
ARQ 531 is presently being evaluated in an open-label, multicenter phase $1 / 2$ trial in patients with a number of B-cell malignancies, including CLL (NCT03162536) [82]. Preclinical data suggest that ARQ 531 may be effective against BTK-resistant CLL and CLL that has undergone Richter transformation [70], as well as against acute myeloid leukemia [83].

As clinical development continues for these next-generation BTK inhibitors, it is hoped that one, or all, may emerge as a treatment option for later-line therapy in patients who have developed resistance to earlier-line therapies such as ibrutinib, acalabrutinib, or venetoclax.

\section{PI3K $\delta$ inhibitors in development}

Given the toxicities observed with currently approved PI3K $\delta$, new drugs in this class are being developed to reduce associated toxicities. Summaries of key clinical trials of these investigational agents can be found in Table 3. One agent in development is umbralisib, an inhibitor of PI3K $\delta$ and casein kinase I isoform epsilon. A phase 2 trial showed that umbralisib monotherapy was effective in patients with CLL who were intolerant to previous kinase-inhibitor treatment [84]. This was the first study to demonstrate that switching to umbralisib from another kinase inhibitor resulted in improved disease control without the recurrence of kinase-inhibitor intolerance toxicities [84]. This level of safety improvement over currently approved PI3K $\delta$ inhibitors may greatly improve the applicability of this class of drugs to CLL treatment regimens.

Umbralisib has also been tested as combination therapy. A phase $1 / 1 \mathrm{~b}$ study of umbralisib in combination with ibrutinib in patients with relapsed or refractory CLL or mantle cell lymphoma found that this treatment combination was well-tolerated and demonstrated activity against disease [85]. This first clinical report of doublet therapy using a BTK inhibitor combined with a PI3K $\delta$ inhibitor indicates that it is a feasible approach, though further studies are warranted. Similarly, an open-label phase 1 study of combination therapy with umbralisib, ublituximab, and ibrutinib found the combination to be tolerable with encouraging activity in advanced CLL and B-cell NHL [86]; however, additional investigation of this chemotherapy-free triplet combination is needed. A recent update of the phase 3 UNITY trial (NCT02612311) reported that treatment with umbralisib plus ublituximab significantly prolonged PFS compared with obinutuzumab plus chlorambucil in patients with CLL who were treatment-naïve or who had relapsed or refractory CLL (median PFS: 31.9 months vs 17.9 months; $p<0.0001$ ) [87].

Another PI3K $\delta$ inhibitor in development is the highly selective ME-401; it is being tested as a once-daily oral treatment [88]. Preclinical in vitro data demonstrated that ME-401 had more potent activity against CLL cells compared with idelalisib or ibrutinib [89], and in preclinical animal models it was shown to bind to the target more tightly than idelalisib [88]. A high objective response rate was reported in a dose-escalation/expansion phase $1 \mathrm{~b}$ clinical trial of patients with B-cell malignancies who were treated with ME-401 either continuously or on an intermittent schedule (NCT02914938) [90, 91]. Importantly, patients on the intermittent schedule (2 months of continuous daily therapy, followed by 7 days of ME- 401 delivery, then 3 weeks off treatment, in every 28-day cycle) were observed to have a significantly reduced incidence of immune-mediated AEs of special interest compared with patients on continuous treatment. Updated data (median follow-up 9.7 months) from those patients on the intermittent schedule reported a low rate of grade 3 severity class-related AEs of special interest and a continued high objective response rate [91]. These data demonstrate that advances in treatment schedules may help reduce toxicity without compromising efficacy.

\section{New approaches in development Novel drug combinations}

Combinations of anti-CD20 and targeted therapies have been evaluated. Venetoclax plus obinutuzumab for a fixed treatment duration of 1 year is approved for treatmentnaïve patients with CLL [48]. Because acalabrutinib has improved kinase selectivity versus ibrutinib [92], and obinutuzumab appears to have improved antibody-dependent cellular toxicity over rituximab [93, 94], evaluation of this combination was warranted. A recently completed phase $1 \mathrm{~b}$ study evaluating acalabrutinib plus obinutuzumab therapy in treatment-naïve patients with relapsed or refractory CLL reported high response rates and durable remissions [95]. The ELEVATE-TN trial evaluated acalabrutinib both as monotherapy and in combination with obinutuzumab [43]. Post hoc analysis revealed that better PFS was observed with the combination; however, the study was not powered to determine statistical significance for the comparison of these 2 treatment arms. Further studies are needed to determine if there is an advantage for combination versus monotherapy and to identify the appropriate patient population.

BCL-2 and BTK-inhibitor combinations have shown promise, particularly in high-risk patients. The phase 2 CLARITY study evaluated ibrutinib plus venetoclax in patients with relapsed or refractory CLL [96]. After 12 months of combination treatment, 19 of 53 (36\%) patients had MRD-negative bone marrow and 28 of 53 (53\%) patients had MRD-negative peripheral blood samples. The depth of MRD reduction improved over time, with 11 of 25 (44\%) patients achieving MRD eradication 
after 24 months of treatment. Another phase 2 trial of ibrutinib plus venetoclax was conducted in treatmentnaïve, high-risk, older patients with CLL [97]. The proportion of patients with undetectable MRD (uMRD) increased over time (ie, with an increased number of treatment cycles). Of the 80 patients enrolled, 59 (74\%) had a best response of complete remission (CR) or CR with incomplete count recovery (CRi). After 18 treatment cycles, 25 of $26(96 \%)$ patients had CR or CRi and 18 of $26(69 \%)$ had bone marrow uMRD. Responses were seen across all high-risk subgroups and no new safety concerns were reported. Longer-term studies are needed to determine if this combination is feasible as a fixedduration therapy option. A phase 1 trial to determine optimal dosing of ibrutinib when venetoclax is added for the treatment of patients with CLL who have progressed on ibrutinib monotherapy (NCT03422393) is ongoing. Numerous other clinical trials evaluating various aspects of BCL-2/BTK-inhibitor combination treatment are underway; it is hoped that these trials will result in promising new treatment options for CLL, including potential fixed-duration treatment options.

Another treatment strategy aiming to achieve a fixedduration treatment time with high rates of deep remission is the use of chemotherapy-free triplet combinations. Phase 2 results from a study evaluating limited duration ( 14 cycles; 28 days/cycle) treatment with ibrutinib, venetoclax, and obinutuzumab in patients who were treatment-naïve and had relapsed or refractory CLL have been published [98]. The ORR was $84 \%$ in treatment-naïve patients and $88 \%$ in patients with relapsed or refractory CLL. uMRD (assessed in both blood and bone marrow) was achieved in $67 \%$ and $50 \%$ of patients, respectively, and treatment was well-tolerated, with $6 \%$ of patients discontinuing because of AEs, most of which were hematological in nature. A phase 2 trial of this triplet therapy in treatment-naïve patients with high-risk CLL (CLL2GIVE) reported encouraging preliminary results, with a CR rate of 59\% (24/41 patients) and uMRD in the peripheral blood in 33 patients (81\%) [99]. Twenty-two patients discontinued treatment at cycle 15 after achieving uMRD and CR or CRi. Phase 3 trials are currently being conducted to compare ibrutinib plus obinutuzumab with and without venetoclax (NCT03701282 and NCT03737981). NCT03701282 will compare MRD and MRD CR rates between treatments as a secondary outcome measure, and NCT03737981 will include MRD analysis. A phase 3 study evaluating multiple venetoclax-containing experimental arms (plus rituximab, plus obinutuzumab, plus ibrutinib and obinutuzumab) versus chemoimmunotherapy in treatment-naïve patients with CLL who do not have del(17p) or TP53 mutation is also ongoing (GAIA/ CLL13 trial, NCT02950051). Studies evaluating triplet combinations using acalabrutinib rather than ibrutinib are also underway. An ongoing phase 2 trial evaluating limited-duration acalabrutinib, venetoclax, and obinutuzumab triplet therapy in treatment-naïve patients with CLL (NCT03580928) has reported updated results: 100\% of patients with at least 16 months of follow-up have responded to treatment, with $43 \%$ acheiving CR/CRi and $57 \%$ achieving partial response. The primary endpoint of bone marrow uMRD CR was achieved by $31 \%$ of patients [100]. Additionally, $84 \%$ of patients achieved peripheral blood uMRD and 78\% achieved bone marrow uMRD. A phase 3 study to evaluate acalabrutinib plus venetoclax with or without obinutuzumab versus chemoimmunotherapy in treatment-naïve patients with CLL was recently initiated (ACE-CL-311, NCT03836261). Other triplet combinations, such as atezolizumab (anti-PD-L1), obinutuzumab, and venetoclax (NCT02846623) are also being investigated in patients with CLL.

\section{MRD-guided treatment approaches}

MRD in CLL is determined by the number of leukemic cells detected in either the peripheral blood or bone marrow and UMRD has been most often defined as $<1$ CLL cell per 10,000 leukocytes [6]. Multiple randomized clinical trials have shown that MRD status after treatment induction is an independent predictor of survival and PFS (reviewed in [101]), and efforts have been made towards determining the feasibility of using an MRD-guided approach to CLL treatment. A retrospective analysis of patients treated with chemoimmunotherapy found that, among patients who achieved UMRD, those who stopped treatment after 3 cycles had PFS and OS outcomes similar to those who received 6 cycles of therapy [102]. Other trials evaluating different strategies for treatment discontinuation after patients achieve uMRD with CR/CRi have shown promising results. Strategies include reduced dosing based on uMRD achievement [103], terminating treatment after uMRD is confirmed in patients with CR/ CRi [104], and limiting treatment duration after becoming MRD negative to the time it took to achieve uMRD [96]. The latter approach is being further evaluated in the ongoing phase 3 FLAIR trial [105]. MRD-guided approaches should take into consideration the impact of specific treatments on MRD predictive value. Additionally, studies investigating the impact of disease biology on the predictive value of MRD are needed to understand which patients will benefit most from MRD-guided treatment [101]. It should be noted that MRD-related outcomes are included in the design of multiple ongoing clinical trials in patients with CLL (eg, NCT03737981 and NCT03701282). Continued MRD analysis in clinical trials may provide valuable information towards determining appropriate MRD-guided treatment protocols. 


\section{Bispecific antibodies}

Unlike monospecific antibodies that bind to a single epitope, bispecific antibodies are able to bind 2 distinct epitopes, allowing dual targeting capabilities [106]. This permits the development of antibodies with novel mechanisms of action, such as bringing 2 cell types together (eg, engaging immune and tumor cells), delivering payloads to target cells, or engaging or blocking 2 different antigens on the same cell [106]. One example of a bispecific antibody that is approved for cancer treatment is the bispecific T-cell engager (BiTE) antibody blinatumomab, which binds both CD19 and CD3 and elicits cytotoxic $\mathrm{T}$ lymphocyte (CTL) activity against CD19-expressing tumor cells $[9,107]$.

The development of bispecific antibodies in the CLL treatment space is currently focused on dual targeting of CD3 and CD20. There are 7 CD3/CD20 antibodies that are currently in phase 1 or $1 / 2$ clinical trials for CLL and/ or NHL [108]. Plamotamab (XmAb13676), a bispecific antibody that binds both CD3 and CD20, is currently being tested in a first-in-human phase 1 clinical study in patients with CLL and NHL (NCT02924402). Interim results indicate evidence of clinical activity in heavily pretreated patients with relapsed or refractory CLL or NHL and AEs were generally manageable. This study is ongoing and further data specifically from the CLL patient population are expected.

Results from phase 1 clinical trials of CD3/CD20 bispecific antibodies odronextamab (REGN1979) and mosunetuzumab in other B-cell malignancies have been reported. A phase 1 study reported that treatment with odronextamab resulted in overall responses and durable CRs (relapsed or refractory diffuse large B-cell lymphoma without prior CAR-T therapy: ORR 60\%; CR 60\%; median duration of CR 9.5 months; relapsed or refractory diffuse large B-cell lymphoma with prior CAR-T therapy: ORR 33\%; CR 24\%; median duration of CR 4.4 months; relapsed or refractory follicular lymphoma: ORR 93\%; CR 75\%; median duration of CR 8.1 months) [109]. A phase 1 clinical trial investigating the safety and tolerability of odronextamab in patients with CLL or NHL is ongoing (NCT02290951). In a phase $1 / 1 \mathrm{~b}$ clinical trial (NCT02500407), patients with relapsed or refractory follicular lymphoma who received fixed-duration mosunetuzumab monotherapy had an ORR of $68 \%$ and a CR rate of $50 \%$. CR rates in high-risk patient populations and in those who had received prior CAR-T therapy were consistent with the overall population of patients with relapsed or refractory follicular lymphoma. The median duration of response was 20.4 months and the median PFS was 11.8 months [110].

\section{CAR T-cell therapies}

CAR-T cell therapy involves collecting autologous or allogeneic T-cells and modifying them to produce CAR fusion proteins consisting of an antigen recognition moiety and T-cell signaling domain, then infusing the engineered T-cells back into the patient. Autologous CAR-T cell therapies directed against CD19 have been tested in patients with CLL and are reported to induce remission in these patients $[10,111]$. CD19-specific CAR-T therapy resulted in remission for 8 of 14 (57\%) patients with heavily pretreated, relapsed or refractory CLL in a pilot/phase 1 study [111] and in remission for 17 of 24 (71\%) patients with CLL who had experienced treatment failure with anti-CD20 antibody, fludarabine, or bendamustine in a phase $1 / 2$ trial [10]. In the phase $1 / 2$ trial, CD19-specific CAR-T therapy showed efficacy in high-risk patients with CLL who did not respond to ibrutinib [10].

An ongoing, open-label, phase 1/2 trial of CD19-specific autologous CAR-T cells in patients with heavily pretreated, relapsed or refractory CLL (TRANSCEND CLL 004; NCT03331198) recently reported updated results for the phase 1 portion of the study [112]. All the patients had received prior ibrutinib treatment and half had failed both prior venetoclax and BTK inhibitor therapy. All reported manageable toxicities. The ORR was $82 \%$ and median PFS was 18 months at a median follow-up of 18 months; $50 \%$ of patients had maintained their responses at 18 months. The phase 2 portion of the study is currently enrolling. Preliminary results for an ongoing phase 1 trial of CD19-specific EGFRt/19-28z/41BBL "armored" CAR-T cells in patients with relapsed or refractory NHL or CLL (NCT03085173) have also been reported [113]. No severe cytokine release events were noted, and the complete response rate was $57 \%$ at the time of reporting. A phase 1 trial (ALLCAR19) of another CD19-specific CAR-T cell treatment (AUTO1) in patients with CLL and other B-cell lymphomas is also ongoing (NCT02935257). Recent preliminary data showed that $84 \%$ of patients with relapsed or refractory B-cell acute lymphocytic lymphoma who were treated with AUTO1 achieved MRD-negative CRs; 58\% of patients remain on-study with continued MRD-negative remission (median follow-up: 12.2 months) [114].

Several clinical trials investigating CAR-T cell therapy in patients with CLL are currently recruiting patients. These include a phase 1/2a trial of CD20-specific CAR-T cells in patients with relapsed or refractory NHL or CLL (NCT04030195), a phase 1 trial of CD19-specific CAR-T cells in patients with CLL or diffuse large B-cell lymphoma (NCT03960840), a phase 1 trial of second- or 
third-generation CD19-specific CAR-T cells in patients with CLL, acute lymphocytic leukemia, or advanced B-cell NHL (NCT01853631), and a phase 1 trial of CD19/ CD20-specific CAR-T cells in patients with relapsed or refractory CLL (NCT04007029).

While CAR-T therapy has shown remarkable efficacy in CLL to date, there can be substantial issues with treatment-related toxicity. Common AEs include cytokinerelease syndrome, B-cell aplasia, neurotoxicity, and infection, all of which can be severe $[115,116]$. Appropriate supportive care and management of toxicities are critical to the success of CAR-T therapy $[115,116]$. In addition to toxicities, manufacture of these patient-specific therapies is costly and takes a significant amount of time, potentially limiting the number of patients who can be treated [117]. Research towards improving the CAR-T production platform is ongoing [117].

\section{CAR-natural killer cell therapies}

Natural killer (NK) cells can also be engineered to express CARs. It is anticipated that these cells may overcome both the toxic effects and manufacturing hurdles associated with CAR-T cell therapy [118]. NK cells play a key role in the innate immune system by targeting cancer cells and virally infected cells that have downregulated human leukocyte antigen class I molecules or that express stress markers. NK cells from an allogeneic source can be administered without the need for full human leukocyte antigen matching, eliminating the requirement for production on a patient-by-patient basis as required by most CAR-T cell therapies.

Early-phase trials of CD19-specific CAR-NK treatment in patients with CLL and NHL showed responses without major toxicity [1118]. CD20-specific CAR-NK cells have also been investigated against primary CLL cells both in vitro and in the Daudi mouse model of Burkitt lymphoma [119, 120]. These cells demonstrated antitumor effects in both cases, demonstrating promise for further preclinical development.

\section{How we treat CLL}

It is important to stay current on new clinical findings; this information will help inform appropriate clinical decisions. In general, we recommend determining treatment sequence based on individual patient characteristics. Current disease status, comorbidities, safety profiles of potential treatments, and patient preferences are important considerations. For example, if a patient with newly diagnosed CLL has a high disease burden, we would recommend against using venetoclax because of the increased risk of tumor lysis. Additionally, some patients, particularly during a pandemic, may not want to be hospitalized for monitoring of tumor lysis. In this case, we would be more likely to recommend oral therapy. If a patient has cardiac disease, we recommend treatment with acalabrutinib rather than venetoclax given the associated cardiac risks with the latter therapy. However, for patients who may prefer therapy over a fixed time period, venetoclax may still be the best option.

\section{Conclusion}

BTK and BCL-2 inhibitors have replaced chemotherapy as the standard-of-care therapy for patients with CLL. In the era of chemotherapy, patients with TP53 dysfunction were considered high risk because chemotherapy was ineffective. These patients are still considered to be at a high risk for progression while receiving kinase inhibitor therapy. BTK inhibitors with improved selectivity, such as the recently approved acalabrutinib, may provide patients with a treatment option having improved tolerability and efficacy compared with ibrutinib. It is hoped that the expanding array of BTK inhibitors in development will allow patients to switch to a different BTK inhibitor if resistance emerges because of acquired mutations.

Other targeted therapies, often combined with antiCD20 therapy, are most useful in patients who have disease progression on a BTK inhibitor, or for whom BTK inhibitors are unsuitable. Combining anti-CD20 with BCL-2 inhibitors offers a short-term alternative to continuous BTK-inhibitor monotherapy. Other targeted therapy combinations such as BCL-2 and BTK inhibitors or triplet combinations that include anti-CD20 also show promise, particularly in high-risk patients. Emerging targeted therapies, such as CD3/CD20 bispecific antibodies, may provide further treatment options. In addition, cell-based therapies may prove able to fill the unmet need for effective treatment in patients who have progressed on BTK inhibitors or other targeted therapies, or who are intolerant of those therapies.

In addition to expanding the number of agents that can be used in the treatment of CLL, research addressing optimal treatment sequence, safety, and efficacy of combination therapies, and modifications of current treatment regimens such as intermittent sequence therapy, is needed to fill the gaps in current knowledge related to treatment decision-making and to address some of the current unmet needs in CLL therapy.

Abbreviations
$\begin{array}{ll}\text { AE } & \text { Adverse event } \\ \text { BCL-2 } & \text { B-cell leukemia/lymphoma } 2 \\ \text { BiTE } & \text { Bispecific T cell engager } \\ \text { BLK } & \text { B lymphocyte kinase } \\ \text { BMX } & \text { Bone marrow tyrosine kinase gene in chromosome } X \\ \text { BTK } & \text { Bruton tyrosine kinase } \\ \text { CAR-T } & \text { Chimeric antigen receptor T-cell }\end{array}$




$\begin{array}{ll}\text { CLL } & \text { Chronic lymphocytic leukemia } \\ \text { CLL-IPI } & \text { Chronic lymphocytic leukemia international prognostic index } \\ \text { CR } & \text { Complete remission } \\ \text { CRi } & \text { Incomplete count recovery } \\ \text { CTL } & \text { Cytotoxic Tymphocyte } \\ \text { EGFR } & \text { Epidermal growth factor receptor } \\ \text { HER2 } & \text { Human EGFR-2 } \\ \text { HER4 } & \text { Human EGFR-4 } \\ \text { HRQoL } & \text { Health-related quality of life } \\ \text { ITK } & \text { Interleukin-2-inducible T-cell kinase } \\ \text { iWCLL } & \text { International Workshop on chronic lymphocytic leukemia } \\ \text { JAK2 } & \text { Janus kinase 2 } \\ \text { MRD } & \text { Minimal residual disease } \\ \text { NHL } & \text { Non-Hodgkin lymphoma } \\ \text { NK } & \text { Natural killer } \\ \text { ORR } & \text { Overall response rate } \\ \text { OS } & \text { Overall survival } \\ \text { PFS } & \text { Progression-free survival } \\ \text { PI3Kס } & \text { Phosphatidylinositol 4,5-bisphosphate 3-kinase catalytic subunit } \\ & \text { delta } \\ \text { SAE } & \text { Serious adverse event } \\ \text { SLL } & \text { Small lymphocytic lymphoma } \\ \text { UMRD } & \text { Undetectable minimal residual disease } \\ \text { WM } & \text { Wäldenstrom macroglobulinemia }\end{array}$

\section{Acknowledgements}

Medical writing support was provided by Amy McQuay, Ph.D., of Oxford PharmaGenesis, Oxford, UK, and was funded by AstraZeneca LP.

\section{Authors' contributions}

JMP and KP conceptualized this review and contributed to the writing and revision of the manuscript. Both authors read and approved the final manuscript.

\section{Funding}

This work was supported by AstraZeneca LP.

\section{Availability of data and materials}

Not applicable.

\section{Declarations}

Ethics approval and consent to participate

Not applicable.

\section{Consent for publication}

Not applicable.

\section{Competing interests}

JMP has consulted for AstraZeneca, Loxo Oncology, BeiGene, and Gilead. KP has consulted for AstraZeneca, BeiGene, Pharmacyclics, Genentech, BMS, Kite, and TG Therapeutics.

\section{Received: 22 December 2020 Accepted: 1 March 2021}

Published: 26 April 2021

\section{References}

1. Hallek M. Chronic lymphocytic leukemia: 2017 update on diagnosis, risk stratification, and treatment. Am J Hematol. 2017:92:946-65.

2. Watson L, Wyld P, Catovsky D. Disease burden of chronic lymphocytic leukaemia within the European Union. Eur J Haematol. 2008:81:253-8.

3. Morton LM, Wang SS, Devesa SS, Hartge P, Weisenburger DD, Linet MS Lymphoma incidence patterns by WHO subtype in the United States, 1992-2001. Blood. 2006;107:265-76.

4. Molica S. Sex differences in incidence and outcome of chronic lymphocytic leukemia patients. Leuk Lymphoma. 2006;47:1477-80.
5. Stevenson FK, Krysov S, Davies AJ, Steele AJ, Packham G. B-cell receptor signaling in chronic lymphocytic leukemia. Blood. 2011;118:4313-20.

6. Hallek M, Cheson BD, Catovsky D, Caligaris-Cappio F, Dighiero G, Dohner H, Hillmen P, Keating M, Montserrat E, Chiorazzi N, et al. iwCLL guidelines for diagnosis, indications for treatment, response assessment, and supportive management of CLL. Blood. 2018;131:2745-60.

7. International CLL-IPI working group. An international prognostic index for patients with chronic lymphocytic leukaemia (CLL-IPI): a metaanalysis of individual patient data. Lancet Oncol. 2016:17:779-90.

8. NCCN guideline with NCCN evidence blocks - chronic lymphocytic leukemia/small lymphocytic lymphoma version 4.2020. https://www. nccn.org/professionals/physician_gls/default.aspx.

9. Robinson HR, Qi J, Cook EM, Nichols C, Dadashian EL, Underbayev C, Herman SEM, Saba NS, Keyvanfar K, Sun C, et al. A CD19/CD3 bispecific antibody for effective immunotherapy of chronic lymphocytic leukemia in the ibrutinib era. Blood. 2018;132:521-32.

10. Turtle CJ, Hay KA, Hanafi LA, Li D, Cherian S, Chen X, Wood B, Lozanski A, Byrd JC, Heimfeld S, et al. Durable molecular remissions in chronic lymphocytic leukemia treated with CD19-specific chimeric antigen receptor-modified T cells after failure of ibrutinib. J Clin Oncol. 2017:35:3010-20

11. Iovino L, Shadman M. Novel therapies in chronic lymphocytic leukemia: a rapidly changing landscape. Curr Treat Options Oncol. 2020;21:24.

12. Binet JL, Auquier A, Dighiero G, Chastang C, Piguet H, Goasguen J, Vaugier G, Potron G, Colona P, Oberling F, et al. A new prognostic classification of chronic lymphocytic leukemia derived from a multivariate survival analysis. Cancer. 1981:48:198-206.

13. Rai KR. A critical analysis of staging in CLL. In: Gale RP, Rai KR, editors. Chronic lymphocytic leukemia: recent progress and future directions. New York: Alan R. Liss; 1987. p. 253-64.

14. Hallek M. Chronic lymphocytic leukemia: 2020 update on diagnosis, risk stratification and treatment. Am J Hematol. 2019;94:1266-87.

15. Frey S, Blankart CR, Stargardt T. Economic burden and quality-of-life effects of chronic lymphocytic leukemia: a systematic review of the literature. Pharmacoeconomics. 2016;34:479-98.

16. Hewison A, Atkin K, McCaughan D, Roman E, Smith A, Smith G, Howell D. Experiences of living with chronic myeloid leukaemia and adhering to tyrosine kinase inhibitors: a thematic synthesis of qualitative studies. Eur J Oncol Nurs. 2020;45:101730-101730.

17. Patel K, Sudhir VS, Kabadi S, Huang JC, Porwal S, Thakkar K, Pagel JM. Impact of dosing frequency (once daily or twice daily) on patient adherence to oral targeted therapies for hematologic malignancies: a retrospective cohort study among managed care enrollees. J Oncol Pharm Pract. 2019;25:1897-906.

18. Kabadi SM, Goyal RK, Nagar SP, Kaye JA, Davis KL. Treatment patterns, adverse events, and economic burden in a privately insured population of patients with chronic lymphocytic leukemia in the United States. Cancer Med. 2019;8:3803-10.

19. Farooqui AA, Ashraf A, Farooq TB, Anjum A, Rehman SU, Akbar A, Kanate A, Dean R, Ahmed MQ, Tariq MJ, et al. Novel targeted therapies for chronic lymphocytic leukemia in elderly patients: a systematic review. Clin Lymphoma Myeloma Leuk. 2020;20(7):e414-e426.

20. Langerbeins P, Bahlo J, Rhein C, Gerwin H, Cramer P, Furstenau M, Al-Sawaf O, von Tresckow J, Fink AM, Kreuzer KA, et al. Ibrutinib versus placebo in patients with asymptomatic, treatment-NAIIVE early stage CLL: primary endpoint results of the phase 3 double-blind randomized CLL12 trial. Hematol Oncol. 2019:37:38-40.

21. Scheffold A, Stilgenbauer S. Revolution of chronic lymphocytic leukemia therapy: the chemo-free treatment paradigm. Curr Oncol Rep. 2020;22:16.

22. Mato AR, Barrientos JC, Ghosh N, Pagel JM, Brander DM, Gutierrez M, Kadish $\mathrm{K}$, Tomlinson B, lyengar $\mathrm{R}$, Ipe $\mathrm{D}$, et al. Prognostic testing and treatment patterns in chronic lymphocytic leukemia in the era of novel targeted therapies: results from the inform CLL Registry. Clin Lymphoma Myeloma Leuk. 2020;20(174-183):e173.

23. Kipps TJ, Fraser G, Coutre SE, Brown JR, Barrientos JC, Barr PM, Byrd JC, O'Brien SM, Dilhuydy MS, Hillmen P, et al. Long-term studies assessing outcomes of ibrutinib therapy in patients with del(11q) chronic lymphocytic leukemia. Clin Lymphoma Myeloma Leuk. 2019;19(715-722):e716. 
24. Ahn IE, Underbayev C, Albitar A, Herman SE, Tian X, Maric I, Arthur DC, Wake L, Pittaluga S, Yuan CM, et al. Clonal evolution leading to ibrutinib resistance in chronic lymphocytic leukemia. Blood. 2017;129:1469-79.

25. FDA approves Imbruvica (ibrutinib) to treat chronic lymphocytic leukemia. https://www.drugs.com/newdrugs/fda-approves-imbruvica-ibrut inib-chronic-lymphocytic-leukemia-4007.html. Accessed 16 Apr 2020.

26. FDA approves Imbruvica (ibrutinib) for the first-line treatment of chronic lymphocytic leukemia. https://www.drugs.com/newdrugs/ fda-approves-imbruvica-ibrutinib-first-line-chronic-lymphocytic-leuke mia-4353.html. Accessed 16 Apr 2020.

27. NCCN guideline with NCCN evidence blocks_chronic lymphocytic leukemia/small lymphocytic lymphoma version 5.2019. https://www. nccn.org/professionals/physician_gls/default.aspx. Accessed $22 \mathrm{Apr}$ 2020

28. Byrd JC, Brown JR, O'Brien S, Barrientos JC, Kay NE, Reddy NM, Coutre S, Tam CS, Mulligan SP, Jaeger U, et al. Ibrutinib versus ofatumumab in previously treated chronic lymphoid leukemia. N Engl J Med. 2014;371:213-23.

29. Burger JA, Tedeschi A, Barr PM, Robak T, Owen C, Ghia P, Bairey O, Hillmen P, Bartlett NL, Li J, et al. Ibrutinib as initial therapy for patients with chronic lymphocytic leukemia. N Engl J Med. 2015;373:2425-37.

30. Moreno C, Greil R, Demirkan F, Tedeschi A, Anz B, Larratt L, Simkovic M, Samoilova O, Novak J, Ben-Yehuda D, et al. Ibrutinib plus obinutuzumab versus chlorambucil plus obinutuzumab in first-line treatment of chronic lymphocytic leukaemia (iLLUMINATE): a multicentre, randomised, open-label, phase 3 trial. Lancet Oncol. 2019;20:43-56.

31. Shanafelt TD, Wang XV, Kay NE, Hanson CA, O'Brien S, Barrientos J, Jelinek DF, Braggio E, Leis JF, Zhang CC, et al. Ibrutinib-rituximab or chemoimmunotherapy for chronic lymphocytic leukemia. N Engl J Med. 2019;381:432-43.

32. Woyach JA, Ruppert AS, Heerema NA, Zhao W, Booth AM, Ding W, Bartlett NL, Brander DM, Barr PM, Rogers KA, et al. Ibrutinib regimens versus chemoimmunotherapy in older patients with untreated CLL. N Engl J Med. 2018;379:2517-28.

33. Hardy-Abeloos C, Pinotti R, Gabrilove J. Ibrutinib dose modifications in the management of CLL. J Hematol Oncol. 2020;13:66.

34. Mato AR, Nabhan C, Thompson MC, Lamanna N, Brander DM, Hill B, Howlett C, Skarbnik A, Cheson BD, Zent C, et al. Toxicities and outcomes of 616 ibrutinib-treated patients in the United States: a real-world analysis. Haematologica. 2018;103:874-9.

35. Nuttall E, Tung J, Trounce E, Johnston R, Chevassut T. Real-world experience of ibrutinib therapy in relapsed chronic lymphocytic leukemia: results of a single-center retrospective analysis. J Blood Med. 2019:10:199-208.

36. Parikh SA, Achenbach SJ, Call TG, Rabe KG, Ding W, Leis JF, Kenderian SS, Chanan-Khan AA, Koehler AB, Schwager SM, et al. The impact of dose modification and temporary interruption of ibrutinib on outcomes of chronic lymphocytic leukemia patients in routine clinical practice. Cancer Med. 2020:9:3390-9.

37. O'Brien SM, Byrd JC, Hillmen P, Coutre S, Brown JR, Barr PM, Barrientos JC, Devereux S, RobakT, Reddy NM, et al. Outcomes with ibrutinib by line of therapy and post-ibrutinib discontinuation in patients with chronic lymphocytic leukemia: phase 3 analysis. Am J Hematol. 2019;94:554-62

38. Tam CS, Trotman J, Opat S, Burger JA, Cull G, Gottlieb D, Harrup R, Johnston PB, Marlton P, Munoz J, et al. Phase 1 study of the selective BTK inhibitor zanubrutinib in B-cell malignancies and safety and efficacy evaluation in CLL. Blood. 2019;134:851-9.

39. FDA approves Calquence for adults with chronic lymphocytic leukemia. https://www.drugs.com/newdrugs/fda-approves-calquence-adultschronic-lymphocytic-leukemia-5110.html. Accessed 16 Apr 2020.

40. Awan FT, Schuh A, Brown JR, Furman RR, Pagel JM, Hillmen P, Stephens DM, Woyach J, Bibikova E, Charuworn P, et al. Acalabrutinib monotherapy in patients with chronic lymphocytic leukemia who are intolerant to ibrutinib. Blood Adv. 2019;3:1553-62.

41. Byrd JC, Harrington B, O'Brien S, Jones JA, Schuh A, Devereux S, Chaves J, Wierda WG, Awan FT, Brown JR, et al. Acalabrutinib (ACP-196) in relapsed chronic lymphocytic leukemia. N Engl J Med. 2016;374:323-32

42. Byrd JC, Wierda WG, Schuh A, Devereux S, Chaves JM, Brown JR, Hillmen P, Martin P, Awan FT, Stephens DM, et al. Acalabrutinib monotherapy in patients with relapsed/refractory chronic lymphocytic leukemia: updated phase 2 results. Blood. 2020;135:1204-13.

43. Sharman JP, Egyed M, Jurczak W, Skarbnik A, Pagel JM, Flinn IW, Kamdar M, Munir T, Walewska R, Corbett G, et al. Acalabrutinib with or without obinutuzumab versus chlorambucil and obinutuzmab for treatmentnaive chronic lymphocytic leukaemia (ELEVATE TN): a randomised, controlled, phase 3 trial. Lancet. 2020;395:1278-91.

44. Ghia P, Pluta A, Wach M, Lysak D, Kozak T, Simkovic M, Kaplan P, Kraychok I, Illes A, De La Serna J, et al. Acalabrutinib vs rituximab plus idelalisib (IdR) or benadmustine (BR) by investigator choice in relapsed/ refractory (RR) chronic lymphocytic leukaemia: results from a preplanned interim analysis of the phase 3 ASCEND study. In: 15th international conference on malignant lymphoma, Lugano, Switzerland; 2019.

45. Rogers KA, Thompson PA, Allan JN, Coleman M, Sharman JP, Cheson BD, Izumi R, Frigault MM, Quah C, Raman RK, et al. Phase 2 study of acalabrutinib in ibrutinib-intolerant patients with relapsed/refractory chronic lymphocytic leukaemia. Hematolog Oncol. 2019;37:60-1.

46. Woyach JA, Furman RR, Liu TM, Ozer HG, Zapatka M, Ruppert AS, Xue L, Li DH, Steggerda SM, Versele M, et al. Resistance mechanisms for the Bruton's tyrosine kinase inhibitor ibrutinib. N Engl J Med. 2014;370:2286-94.

47. Woyach JA, Ruppert AS, Guinn D, Lehman A, Blachly JS, Lozanski A, Heerema NA, Zhao W, Coleman J, Jones D, et al. BTK(C481S)-mediated resistance to ibrutinib in chronic lymphocytic leukemia. J Clin Oncol. 2017:35:1437-43.

48. AbbVie announces US FDA approval of Venclexta (venetoclax) as a chemotherapy-free combination regimen for previously untreated chronic lymphocytic leukemia patients. https://www.drugs.com/newdr ugs/abbvie-announces-us-fda-approval-venclexta-venetoclax-chemo therapy-free-combination-regimen-4974.html. Accessed 15 June 2020.

49. Stilgenbauer S, Eichhorst B, Schetelig J, Coutre S, Seymour JF, Munir T, Puvvada SD, Wendtner CM, Roberts AW, Jurczak W, et al. Venetoclax in relapsed or refractory chronic lymphocytic leukaemia with $17 \mathrm{p}$ deletion: a multicentre, open-label, phase 2 study. Lancet Oncol. 2016;17:768-78.

50. Stilgenbauer S, Eichhorst B, Schetelig J, Hillmen P, Seymour JF, Coutre S, Jurczak W, Mulligan SP, Schuh A, Assouline S, et al. Venetoclax for patients with chronic lymphocytic leukemia with 17p deletion: results from the full population of a phase II pivotal trial. J Clin Oncol. 2018;36:1973-80.

51. Fischer K, Al-Sawaf O, Bahlo J, Fink A-M, Tandon M, Dixon M, Robrecht S, Warburton S, Humphrey K, Samoylova O, et al. Venetoclax and obinutuzumab in patients with CLL and coexisting conditions. N Engl J Med. 2019;380:2225-36

52. Al-Sawaf O, Zhang C, Tandon M, Sinha A, Fink A-M, Robrecht S, Tausch E, Schary WL, Ritgen M, Wendtner CM, et al. Fixed-duration venetoclax-obinutuzumab for previously untreated patients with chronic lymphocytic leukemia: follow-up of efficacy and safety results from the multicenter, open-label, randomized, phase III CLL14 trial. J Clin Oncol. 2020;38:8027

53. Mato AR, Thompson M, Allan JN, Brander DM, Pagel JM, Ujjani CS, Hill BT, Lamanna N, Lansigan F, Jacobs R, et al. Real-world outcomes and management strategies for venetoclax-treated chronic lymphocytic leukemia patients in the United States. Haematologica. 2018;103:1511-7.

54. Jones JA, Mato AR, Wierda WG, Davids MS, Choi M, Cheson BD, Furman RR, Lamanna N, Barr PM, Zhou L, et al. Venetoclax for chronic lymphocytic leukaemia progressing after ibrutinib: an interim analysis of a multicentre, open-label, phase 2 trial. Lancet Oncol. 2018;19:65-75.

55. FDA approves Zydelig. https://www.drugs.com/newdrugs/fda-appro ves-zydelig-idelalisib-cll-lymphoma-4056.html. Accessed 22 Apr 2020

56. Furman RR, Sharman JP, Coutre SE, Cheson BD, Pagel JM, Hillmen P, Barrientos JC, Zelenetz AD, Kipps TJ, Flinn I, et al. Idelalisib and rituximab in relapsed chronic lymphocytic leukemia. N Engl J Med. 2014;370:997-1007.

57. Lampson BL, Kasar SN, Matos TR, Morgan EA, Rassenti L, Davids MS, Fisher DC, Freedman AS, Jacobson CA, Armand P, et al. Idelalisib given front-line for treatment of chronic lymphocytic leukemia causes frequent immune-mediated hepatotoxicity. Blood. 2016;128:195-203. 
58. Lampson BL, Matos T, Kim HT, Kasar S, Morgan EA, Hirakawa M, Fein J, Fernandes SM, Ritz J, Brown JR. Idelalisib given front-line for the treatment of chronic lymphocytic leukemia results in frequent and severe immune-mediated toxicities. Blood. 2015;126:497.

59. Jones JA, Robak T, Brown JR, Awan FT, Badoux X, Coutre S, Loscertales J, Taylor K, Vandenberghe E, Wach M, et al. Efficacy and safety of idelalisib in combination with ofatumumab for previously treated chronic lymphocytic leukaemia: an open-label, randomised phase 3 trial. Lancet Haematol. 2017;4:e114-26.

60. Sharman JP, Coutre SE, Furman RR, Cheson BD, Pagel JM, Hillmen P, Barrientos JC, Zelenetz AD, Kipps TJ, Flinn IW, et al. Final results of a randomized, phase III study of rituximab with or without idelalisib followed by open-label idelalisib in patients with relapsed chronic lymphocytic leukemia. J Clin Oncol. 2019;37:1391-402.

61. Zelenetz AD, Barrientos JC, Brown JR, Coiffier B, Delgado J, Egyed M, Ghia P, Illes A, Jurczak W, Marlton P, et al. Idelalisib or placebo in combination with bendamustine and rituximab in patients with relapsed or refractory chronic lymphocytic leukaemia: interim results from a phase 3, randomised, double-blind, placebo-controlled trial. Lancet Oncol. 2017; 18:297-311.

62. Mato AR, Hill BT, Lamanna N, Barr PM, Ujjani CS, Brander DM, Howlett C, Skarbnik AP, Cheson BD, Zent CS, et al. Optimal sequencing of ibrutinib, idelalisib, and venetoclax in chronic lymphocytic leukemia: results from a multicenter study of 683 patients. Ann Oncol. 2017;28:1050-6.

63. FDA approves Copiktra (duvelisib) capsules for chronic lymphocytic leukemia/small lymphocytic lymphoma and follicular lymphoma. https://www.drugs.com/newdrugs/fda-approves-copiktra-duvelisibcapsules-chronic-lymphocytic-leukemia-small-lymphocytic-lymph oma-4822.html. Accessed 15 June 2020.

64. Flinn IW, Hillmen P, Montillo M, Nagy Z, Illes A, Etienne G, Delgado J, Kuss BJ, Tam CS, Gasztonyi Z, et al. The phase 3 DUO trial: duvelisib vs ofatumumab in relapsed and refractory CLL/SLL. Blood. 2018;132:2446-55.

65. Davids MS, Kuss BJ, Hillmen P, Montillo M, Moreno C, Essell J, Lamanna N, Nagy Z, Tam CS, Stilgenbauer S, et al. Efficacy and Safety of Duvelisib Following Disease Progression on Ofatumumab in Patients with Relapsed/Refractory CLL or SLL in the DUO Crossover Extension Study. Clin Cancer Res. 2020;26:2096-103.

66. Patel K, Danilov AV, Pagel JM. Duvelisib for CLL/SLL and follicular nonHodgkin lymphoma. Blood. 2019;134:1573-7.

67. Patel K, Pagel JM. Exploring a future for PI3K inhibitors in chronic lymphocytic leukemia. Curr Hematol Malig Rep. 2019;14:292-301.

68. Lin VS, Lew TE, Handunnetti SM, Blombery P, Nguyen T, Westerman DA, Kuss BJ, Tam CS, Roberts AW, Seymour JF, Anderson MA. BTK inhibitor therapy is effective in patients with CLL resistant to venetoclax. Blood. 2020:135:2266-70.

69. Gomez EB, Isabel L, Rosendahal SM, Andrews SW, Brandhuber BJ. Loxo305, a highly selective and non-covalent next generation BTK inhibitor, inhibits diverse BTK C481 substitution mutations. Blood. 2019;134:4644.

70. Reiff SD, Mantel R, Smith LL, Greene JT, Muhowski EM, Fabian CA, Goettl VM, Tran M, Harrington BK, Rogers KA, et al. The BTK inhibitor ARQ 531 targets ibrutinib-resistant CLL and Richter transformation. Cancer Discov. 2018:8:1300-15.

71. Mato AR, Flinn IW, Pagel JM, Brown JR, Cheah CY, Coombs CC, Patel MR, Rothenberg SM, Tsai DE, Ku NC, Wang ML. Results from a first-in-human, proof-of-concept phase 1 trial in pretreated B-cell malignancies for Loxo-305, a next-generation, highly selective, non-covalent BTK inhibitor. Blood. 2019;134:501.

72. Woyach J, Stephens DM, Flinn I, Bhat SA, Savage RE, Chai F, Eathiraj S, Granlund L, Szuszkiewicz LA, Schwartz B, Byrd JC. Final results of phase 1, dose escalation study evaluating ARQ 531 in patients with relapsed or refractory B-cell lymphoid malignancies. Blood. 2019;134(1):4298.

73. Syed YY. Zanubrutinib: first approval. Drugs. 2020;80:91-7.

74. Hillmen P, Brown JR, Eichhorst BF, Lamanna N, O'Brien SM, Qiu L, Salmi T, Hilger J, Wu K, Cohen A, et al. ALPINE: zanubrutinib versus ibrutinib in relapsed/refractory chronic lymphocytic leukemia/small lymphocytic lymphoma. Future Oncol. 2020;16:517-23.

75. Zou Y-X, Zhu H-Y, Li X-T, Xia Y, Miao K-R, Zhao S-S, Wu Y-J, Wang L, Xu W, Li J-Y. The impacts of zanubrutinib on immune cells in patients with chronic lymphocytic leukemia/small lymphocytic lymphoma. Hematol Oncol. 2019;37:392-400.
76. Brown JR, RobakT, Ghia P, Kahl BS, Walker P, Janowski W, Chan H, Shadman M, Ganly PS, Laurenti L, et al. Efficacy and safety of zanubrutinib in patients with treatment-naïve (TN) chronic lymphocytic leukemia (CLL) or small lymphocytic lymphoma (SLL) with del(17p): follow-up results from arm C of the SEQUOIA (BGB-3111-304) trial. Blood. 2020;136:11-2.

77. Tam CS, LeBlond V, Novotny W, Owen RG, Tedeschi A, Atwal S, Cohen A, Huang J, Buske C. A head-to-head Phase III study comparing zanubrutinib versus ibrutinib in patients with Waldenström macroglobulinemia. Future Oncol. 2018;14:2229-37.

78. Tam C, Opat S, D'Sa S, Jurczak W, Lee H-P, Cull G, Owen RG, Marlton P, Wahlin BE, Tedeschi A, et al. ASPEN: results of a phase III randomized trial of zanubrutinib versus ibrutinib for patients with Waldenström macroglobulinemia (WM). J Clin Oncol. 2020;38:8007.

79. Xu W, Song Y, Wang T, Yang S, Liu L, Hu Y, Zhang W, Zhou J, Gao S, Ding K, et al. Updated results from the phase II study of orelabrutinib monotherapy in Chinese patients with relapsed or refractory chronic lymphocytic leukemia/small cell leukemia. Blood. 2020;136:26-7.

80. Uhm J. Recent advances in chronic lymphocytic leukemia therapy. Blood Res. 2020;55:S72-s82.

81. Mato AR, Pagel JM, Coombs CC, Shah NN, Lamanna N, Lech-Maranda E, Eyre TA, Woyach JA, Wierda WG, Cheah CY, et al. LOXO-305, a next generation, highly selective, non-covalent BTK inhibitor in previously treated CLL/SLL: results from the phase 1/2 BRUIN study. Blood. 2020;136:35-7.

82. A Study of ARQ 531 in Patients With Selected Hematologic Malignancies. https://ClinicalTrials.gov/show/NCT03162536. Accessed 7 Mar 2021.

83. Elgamal OA, Mehmood A, Jeon JY, Carmichael B, Lehman A, Orwick SJ, Truxall J, Goettl VM, Wasmuth R, Tran M, et al. Preclinical efficacy for a novel tyrosine kinase inhibitor, ArQule 531 against acute myeloid leukemia. J Hematol Oncol. 2020;13:8.

84. Mato AR, Ghosh N, Schuster SJ, Lamanna N, Pagel JM, Flinn IW, Barrientos J, Rai KR, Reeves JA, Cheson BD, et al. Phase 2 study of the safety and efficacy of umbralisib in patients with CLL who are intolerant to BTK or PI3Kdelta inhibitor therapy. Blood. 2020;blood.2020007376.https://doi. org/10.1182/blood.2020007376

85. Davids MS, Kim HT, Nicotra A, Savell A, Francoeur K, Hellman JM, Bazemore J, Miskin HP, Sportelli P, Stampleman L, et al. Umbralisib in combination with ibrutinib in patients with relapsed or refractory chronic lymphocytic leukaemia or mantle cell lymphoma: a multicentre phase 1-1b study. Lancet Haematol. 2019;6:e38-47.

86. Nastoupil $L$, Lunning MA, Vose JM, Schreeder MT, Siddiqi T, Flowers CR, Cohen JB, Burger JA, Wierda WG, O'Brien S, et al. Tolerability and activity of ublituximab, umbralisib, and ibrutinib in patients with chronic lymphocytic leukaemia and non-Hodgkin lymphoma: a phase 1 dose escalation and expansion trial. Lancet Haematol. 2019;6:e100-9.

87. Gribben JG, Jurczak W, Jacobs RW, Grosicki S, Giannopoulos K, Wrobel T, Zafar SF, Cultrera JL, Kambhampati S, Danilov AV, et al. Umbralisib plus ublituximab (U2) is superior to obinutuzumab plus chlorambucil $(\mathrm{O}+\mathrm{Chl})$ in patients with treatment naïve (TN) and relapsed/refractory (R/R) chronic lymphocytic leukemia (CLL): results from the phase 3 Unity-CLL study. Blood. 2020;136:37-9.

88. Moreno O, Wood J. Absorption, distribution, and binding profile of ME-401, a potent and selective oral small-molecule inhibitor of phosphatidylinositol 3-kinase delta (PI3Kdelta) in animal and B-cell lymphoma models. Target Oncol. 2019;14:603-11.

89. O'Farrell M, Ventura R, Tai A, Tyner JW, Loriaux MM, Mahadevan D, Morales C, Brown SD, Matthews DJ. Preclinical characterization of PWT143, a novel selective and potent phosphatidylinositol 3-kinase delta (PI3K delta) inhibitor with ex-vivo activity in hematologic malignancies. Blood. 2012;120:2907.

90. Soumerai JD, Pagel JM, Jagadeesh D, Salman HS, Kenkre VP, Asch AS, Stathis A, Reddy NM, lasonos A, Ghalie R, Zelenetz AD. Initial results of a dose escalation study of a selective and structurally differentiated PI3K $\delta$ inhibitor, ME-401, in relapsed/refractory (R/R) follicular lymphoma (FL) and chronic lymphocytic leukemia (CLL)/small lymphocytic lymphoma (SLL). J Clin Oncol. 2018;36:7519.

91. Zelenetz AD, Reddy NM, Jagadeesh D, Stathis A, Salman HS, Soumerai JD, Kenkre VP, Asch AS, Llorin-Sangalang J, Li J, et al. Tolerability and durable respones of the $\mathrm{PI} 3 \mathrm{~K} \delta$ inhibitor ME-401 administered on an 
intermittent schedule in relapsed/refractory (R/R) follicular lymphoma (FL) and other B-cell malignancies. J Clin Oncol. 2020;38:8016.

92. Kaptein A, Bruin G, van Hoek ME, van de Kar B, de Jong A, Gulrajani M, Demont D, Covey T, Mittag D, Barf T. Potency and selectivity of BTK inhibitors in clinical development for B-cell malignancies. Blood. 2018;132:1871-1871.

93. Bologna L, Gotti E, Manganini M, Rambaldi A, Intermesoli T, Introna M, Golay J. Mechanism of action of type II, glycoengineered, anti-CD20 monoclonal antibody GA101 in B-chronic lymphocytic leukemia whole blood assays in comparison with rituximab and alemtuzumab. J Immunol. 2011;186:3762-9.

94. Rafiq S, Butchar JP, Cheney C, Mo X, Trotta R, Caligiuri M, Jarjoura D, Tridandapani S, Muthusamy N, Byrd JC. Comparative assessment of clinically utilized CD20-directed antibodies in chronic lymphocytic leukemia cells reveals divergent NK cell, monocyte, and macrophage properties. J Immunol. 2013;190:2702-11.

95. Woyach JA, Blachly JS, Rogers KA, Bhat SA, Jianfar M, Lozanski G, Weiss DM, Andersen BL, Gulrajani M, Frigault MM, et al. Acalabrutinib plus obinutuzumab in treatment-naive and relapsed/refractory chronic lymphocytic leukemia. Cancer Discov. 2020;10:394-405.

96. Hillmen P, Rawstron AC, Brock K, Munoz-Vicente S, Yates FJ, Bishop R, Boucher R, MacDonald D, Fegan C, McCaig A, et al. Ibrutinib plus venetoclax in relapsed/refractory chronic lymphocytic leukemia: the CLARITY study. J Clin Oncol. 2019;37:2722-9.

97. Jain N, Keating M, Thompson P, Ferrajoli A, Burger J, Borthakur G, Takahashi K, Estrov Z, Fowler N, Kadia T, et al. Ibrutinib and venetoclax for first-line treatment of CLL. N Engl J Med. 2019;380:2095-103.

98. Rogers KA, Huang Y, Ruppert AS, Abruzzo LV, Andersen BL, Awan FT, Bhat SA, Dean A, Lucas M, Banks C, et al. Phase II study of combination obinutuzumab, ibrutinib, and venetoclax in treatment-naive and relapsed or refractory chronic lymphocytic leukemia. J Clin Oncol. 2020;38:3626-37.

99. Huber H, Edenhofer S, von Tresckow J, Grimm M, Zhang C, Robrecht S, Furstenau M, Dreger P, Ritgen M, IIImer T, et al. CLL2-GIVE, a prospective, open-label, multicenter phase-II trial of obinutuzumab (GA101, G), ibrutinib (I), plus venetoclax (VE) in untreated patients with CLL with 17 P deletion/TP53 mutation. In: EHA25 Virtual; 2020.

100. Davids MS, Lampson BL, Tyekucheva S, Crombie JL, Ng S, Kim Al, Weinstock M, Lowney J, Pazienza S, Montegaard J, et al. Updated safety and efficacy results from a phase 2 study of acalabrutinib, venetoclax and obinutuzumab (AVO) for frontline treatment of chronic lymphocytic leukemia (CLL). Blood. 2020;136:20-1.

101. Furstenau M, De Silva N, Eichhorst B, Hallek M. Minimal residual disease assessment in CLL: ready for use in clinical routine? Hemasphere. 2019;3:e287.

102. Strati P, Keating MJ, O'Brien SM, Burger J, Ferrajoli A, Jain N, Tambaro FP, Estrov Z, Jorgensen J, Challagundla P, et al. Eradication of bone marrow minimal residual disease may prompt early treatment discontinuation in CLL. Blood. 2014;123:3727-32.

103. Jain N, Thompson PA, Burger JA, Ferrajoli A, Takahashi K, Estrov ZE, Borthakur GM, Bose P, Kadia TM, Pemmaraju N, et al. Ibrutinib, fludarabine, cyclophosphamide, and obinutuzumab (iFCG) for first-line treatment of IGHV-mutated CLL and without Del(17p)/mutated TP53. Blood. 2019;134:357.

104. Cramer P, von Tresckow J, Bahlo J, Robrecht S, Langerbeins P, Al-Sawaf $\mathrm{O}$, Engelke A, Fink AM, Fischer K, Tausch E, et al. Bendamustine followed by obinutuzumab and venetoclax in chronic lymphocytic leukaemia (CLL2-BAG): primary endpoint analysis of a multicentre, open-label, phase 2 trial. Lancet Oncol. 2018;19:1215-28.

105. Collett L, Howard DR, Munir T, MCParland L, Oughton JB, Rawstron AC, Hockaday A, Dimbleby C, Phillips D, McMahon K, et al. Assessment of ibrutinib plus rituximab in front-line CLL (FLAIR trial): study protocol for a phase III randomised controlled trial. Trials. 2017;18:387.

106. Suurs FV, Lub-de Hooge MN, de Vries EGE, de Groot DJA. A review of bispecific antibodies and antibody constructs in oncology and clinical challenges. Pharmacol Ther. 2019;201:103-19.

107. Emole JN, Locke FL, Pinilla-lbarz J. An update on current and prospective immunotherapies for chronic lymphocytic leukemia. Immunotherapy. 2015;7:455-66.
108. Lejeune M, Kose MC, Duray E, Einsele H, Beguin Y, Caers J. Bispecific, T-cell-recruiting antibodies in B-cell malignancies. Front Immunol. 2020;11:762.

109. Bannerji R, Allan JN, Arnason JE, Brown JR, Advani R, Ansell SM, O'Brien SM, Duell J, Martin P, Joyce RM, et al. Odronextamab (REGN1979), a human CD20 x CD3 bispecific antibody, induces durable, complete responses in patients with highly refractory B-cell non-Hodgkin lymphoma, including patients refractory to CART therapy. Blood. 2020;136:42-3.

110. Assouline SE, Kim WS, Sehn LH, Schuster SJ, Yoon C, Cheah CY, Nastoupil LJ, Shadman M, Yoon S-S, Matasar MJ, et al. Mosunetuzumab shows promising efficacy in patients with multiply relapsed follicular lymphoma: updated clinical experience from a phase I dose-escalation trial. Blood. 2020;136:42-4.

111. Porter DL, Hwang WT, Frey NV, Lacey SF, Shaw PA, Loren AW, Bagg A, Marcucci KT, Shen A, Gonzalez V, et al. Chimeric antigen receptor T cells persist and induce sustained remissions in relapsed refractory chronic lymphocytic leukemia. Sci Transl Med. 2015;7:303ra139.

112. Siddiqi T, Soumerai JD, Dorritie KA, Stephens DM, Riedell PA, Arnason JE, Kipps TJ, Gillenwater HH, Gong L, Yang L, et al. Updated follow-up of patients with relapsed/refractory chronic lymphocytic leukemia/small lymphocytic lymphoma treated with lisocabtagene maraleucel in the phase 1 monotherapy cohort of transcend CLL 004, including high-risk and ibrutinib-treated patients. Blood. 2020;136:40-1.

113. Batlevi CL, Palomba ML, Park J, Mead E, Santomasso B, Riviere I, Wang X, Senechal B, Furman RR, Yang J, et al. Phase I clinical trial of CD-19 targeted 19-28Z/4-1BBL "armored" CART cells in patients with relapsed or refractory $\mathrm{NHL}$ and $\mathrm{CLL}$ including richter transormation. Hematol Oncol. 2019;37:166-7.

114. Roddie C, O'Reilly MA, Marzolini MAV, Wood L, Dias J, Garai AC, Bosshard L, Abbasian M, Lowdell MW, Wheeler G, et al. ALLCAR19: updated data using AUTO1, a Novel Fast-Off Rate CD19 CAR in relapsed/refractory B-cell acute lymphoblastic leukaemia and other B-cell malignancies. Blood. 2020;136:3-4.

115. Zou Y, Xu W, Li J. Chimeric antigen receptor-modified T cell therapy in chronic lymphocytic leukemia. J Hematol Oncol. 2018;11:130.

116. Brudno JN, Kochenderfer JN. Recent advances in CART-cell toxicity: mechanisms, manifestations and management. Blood Rev. 2019;34:45-55.

117. Makita S, Imaizumi K, Kurosawa S, Tobinai K. Chimeric antigen receptor T-cell therapy for B-cell non-Hodgkin lymphoma: opportunities and challenges. Drugs Context. 2019:8:212567.

118. Liu E, Marin D, Banerjee P, Macapinlac HA, Thompson P, Basar R, Nassif Kerbauy L, Overman B, Thall P, Kaplan M, et al. Use of CAR-transduced natural killer cells in CD19-positive lymphoid tumors. N Engl I Med. 2020:382:545-53.

119. Kloess S, Kretschmer A, Stahl L, Fricke S, Koehl U. CAR-expressing natural killer cells for cancer retargeting. Transfus Med Hemother. 2019;46:4-13.

120. Boissel L, Betancur-Boissel M, Lu W, Krause DS, Van Etten RA, Wels WS, Klingemann H. Retargeting NK-92 cells by means of CD19- and CD20specific chimeric antigen receptors compares favorably with antibodydependent cellular cytotoxicity. Oncoimmunology. 2013;2:e26527.

\section{Publisher's Note}

Springer Nature remains neutral with regard to jurisdictional claims in published maps and institutional affiliations. 